\title{
Using green infrastructure to stimulate discourse with and for planning practice: experiences with fuzzy concepts from a pan-European, a national and a local perspective
}

\author{
Rieke Hansen $^{1}$ (D) Martina van Lierop ${ }^{2}$ (D) . Werner Rolf ${ }^{2}$ (D) Damjana Gantar ${ }^{3}$ (D) - Ina Šuklje Erjavec ${ }^{3}$ (D) \\ Emily Lorance Rall ${ }^{4}$. Stephan Pauleit ${ }^{2}$ (D)
}

Received: 25 September 2020 / Accepted: 17 May 2021 / Published online: 21 June 2021

(c) The Author(s) 2021

\begin{abstract}
Concepts such as green infrastructure, nature-based solutions, and ecosystem services gained popularity in recent discourses on urban planning. Despite their recognition as innovative concepts, all of them share a degree of ambiguity. Fuzziness can be a weakness but also an opportunity to shape novel concepts together with the stakeholders that are supposed to implement them in the planning practice. The paper traces concept development processes of green infrastructure through transdisciplinary knowledge exchange in three different projects, a European and a national research project and a local city-regional project as part of an EU regional cooperation project. In all projects, the green infrastructure concept evolved in different stages. Stakeholder involvement during these stages span from consultation to co-creation. The cases reveal two different approaches: concepts that are developed "for planning practice" might be based on a plethora of insight via consultation, while those "with planning practice" foster co-creation and might result in high acceptance among the involved stakeholders. Depending on the purpose of the novel concept, each approach can be beneficial and result in practice-related and operational products, such as guidance documents or planning strategies. However, the cases also show that in any new context an exchange about fuzzy concepts is not only needed but also a chance to stimulate cooperation and joint understanding about urban challenges and how to address them.
\end{abstract}

Keywords Boundary object $\cdot$ Knowledge exchange $\cdot$ Concept implementation $\cdot$ Transdisciplinarity $\cdot$ Landscape planning

\section{Novel concepts and planning realities}

Concepts such as green infrastructure (GI), nature-based solutions (NBS), and ecosystem services (ES) emphasize the importance of nature and its governance as an integral part of sustainable city regions (Nesshöver et al. 2017; Pauleit et al. 2017; Eggermont et al. 2015). Taking the example of

Rieke Hansen

rieke.hansen@hs-gm.de

1 Institute for Open Space Development, Hochschule Geisenheim University, Geisenheim, Germany

2 Chair for Strategic Landscape Planning and Management, Technical University of Munich, Freising, Germany

3 Urban Planning Institute of the Republic of Slovenia, Ljubljana, Slovenia

4 Regionalverband Ostwürttemberg, Schwäbisch-Gmünd, Germany
GI, it is discussed in science, planning, and policy arenas across the world as an approach that can better help protect nature and promote sustainable and livable cities (e.g., Meerow 2020; Breen et al. 2020; Lindley et al. 2018; Shi 2020; Liao 2019). However, as concepts like GI enter a novel context, they face established planning practices and often create questions about their meaning, added value and how they can be implemented (Luederitz et al. 2015, pp. 108-109; Sussams et al. 2015, pp. 188-189; Wright 2011, p. 1013).

Based on principles from landscape ecology, GI emerged in the 1990s as a planning response to urban sprawl in the USA (Benedict and McMahon 2006; Walmsley 2006). Still, the concept holds a significant degree of ambiguity, as the arenas of science, policy, and planning pursue different rationales and interests (Seiwert and Rößler 2020, p. 2 ). In the last decade, it was considered for different policy and planning contexts, broadening its interpretation, and operationalization beyond the specific problems of spatial planning in the USA (e.g., Breen et al. 2020, p. 13; Lindley 
et al. 2018; Sussams et al. 2015, p. 185; Hansen and Pauleit 2014, pp. 516-517; Wright 2011, pp. 1003-1009). Ongoing debates concern, for instance, whether GI should have an ecological focus with priority on biodiversity conservation (e.g., Garmendia et al. 2016, pp. 317-318) or whether it is stronger on socio-cultural and economic aspects (e.g., EEA 2011, p. 24; Mell 2009, p. 24). In an urban context, GI has been understood as a strategic approach to open space or landscape planning to fulfil a wide range of ecological, social, and economic objectives as well as a narrowly focused spatial solution to local storm water management (Fletcher et al. 2015, p. 533). A broad variety of normative and operational principles have been suggested for GI, with overlaps but without consensus (e.g., Roe and Mell 2013, pp. 653-654; Pauleit et al. 2011, p. 274; Kambites and Owen 2006, p. 488). Nevertheless, it is hoped that the GI concept can bring different sectors and disciplines in spatial planning closer together to find common ground (e.g., Pauleit et al. 2011, pp. 274-275; Kambites and Owen 2006, p. 490).

In the European Union, GI became adopted as a "strategically planned network of natural and semi-natural areas with other environmental features designed and managed to deliver a wide range of ecosystem services" (European Commission 2011, p. 3). ${ }^{1}$ In this understanding, the GI concept is a holistic approach that widens species- and habitat-centered conservation to better align it with a variety of societal demands and economic aspects (Sundseth and Sylwester 2009, pp. 4-6). Despite this high-level policy support and attention in academia, there is no systematic overview on how the concept has been taken up in planning practice in different European countries during the last ten years (exceptions include Davies et al. 2015; Nordh and Olafsson 2020 on Scandinavian countries and reports from single countries such as Lennon 2014 for Ireland or Gavrilidis et al. 2020 for Romania). This is also complicated by the fact that similar approaches such as ecological networks and green space planning had been implemented before in many countries (Nordh and Olafsson 2020; Grădinaru and Hersperger 2018), p. 21).

Scholars have put effort into developing coherent GI definitions and conceptual frameworks, while others argue that maintaining flexibility of the concept might support more adapted solutions (Seiwert and Rößler 2020, p. 7; Sussams et al. 2015, p. 192). In the context of spatial planning, on the one hand, new knowledge needs to correspond with complex planning realities, which are highly context-specific and require solutions for different biophysical, social, and economic constellations, conflicting interests and normative

\footnotetext{
${ }^{1}$ For more detail on the European Strategy on Green Infrastructure and related efforts, including studies and publications, see https://ec. europa.eu/environment/nature/ecosystems/index_en.htm.
}

values (Lindley et al. 2018; Davoudi 2015, p. 12; Lennon 2014, p.17). On the other hand, scientific inquiry requires a certain level of conceptual coherence as a basis for comparative analysis (Brand and Jax 2007, p. 9; Markusen 1999, p. 870). Consequently, depending on the perspective, the fuzziness of concepts is either considered as an opportunity or a weakness that needs to be overcome.

Prior studies on GI, ES, or NBS with a focus on their conceptual ambiguity concern theoretical and analytical foundations, overwhelmingly with single-case applications (Steger et al. 2018; Wright 2011). Opdam et al. (2015) used three cases to shed light on the role of landscape as a concept for knowledge integration and negotiation in planning processes. A few studies have touched on factors that pushed the development and application of ES in different cities and how fuzziness of the concept helped the discourse evolve (e.g., Rall et al. 2015). In particular, the question of how fuzzy concepts can support knowledge exchange between the arenas of science, policy, and planning remains unanswered.

In this paper, we investigate this question by analyzing transdisciplinary discourses on GI in urban regions within three European research projects. Our aim is to utilize the experiences from these projects to better understand the potential of fuzzy concepts in transdisciplinary knowledge exchanges. Based on insights from theory, we develop an analytical model for fuzzy concept development stages. We then analyze each project based on this model. The findings are used to discuss crucial moments in time and supportive activities for steering such discourses. Conclusions are drawn on how to utilize fuzzy concepts for advancing sustainable planning and environmental governance in urban regions.

\section{Analytical model and study approach for fuzzy concepts}

\subsection{Theoretical background and analytical approach}

With this paper, we build on an extensive knowledge base regarding fuzzy concepts and similar approaches. We first define those terms and then describe properties of fuzzy concepts and their evolution over time. From this, we derive our analytical approach, tailored to planning contexts.

\subsubsection{Overlapping terminology}

Fuzzy concepts, boundary objects, and contested concepts all describe terms that possess more than one meaning, but usually hold shared core ideas (Jacobs 2011, p. 26, Star 2010, p. 602-603; Markusen 1999, p. 870). A common definition for boundary objects is that they are analytic 
Table 1 Contexts in which academic papers refer to analytical concepts for ambiguity (BO-boundary object; CC-contested concept; FC-fuzzy concept) and novel approaches (ES-ecosystem services; GI-green infrastructure; NBS-nature-based solutions)

\begin{tabular}{|c|c|c|c|}
\hline Purpose & References & Main approach & $\begin{array}{l}\text { Ana- } \\
\text { lytical } \\
\text { concept }\end{array}$ \\
\hline \multirow[t]{5}{*}{ Further development of novel concept } & Abson et al. (2014) & Literature analysis: academic ES literature & BO \\
\hline & Luederitz et al. (2015) & Case studies: ES cases found in academic literature & $\mathrm{CC}$ \\
\hline & Schröter et al. (2014) & Perspective: arguments for ES concept & $\mathrm{CC}$ \\
\hline & Nesshöver et al. (2017) & Perspective: suggestions for application of NBS concept & $\mathrm{CC}$ \\
\hline & Robinson et al. (2013) & Literature analysis: academic ES literature & FC \\
\hline \multirow[t]{2}{*}{ Uptake of novel concepts in planning } & Wright (2011) & Case study: GI planning discourse in England & $\mathrm{CC}$ \\
\hline & Horwood (2011) & Case study: GI planning discourse in northwest UK & FC \\
\hline \multirow[t]{2}{*}{ Transdisciplinary collaboration } & Steger et al. (2018) & $\begin{array}{l}\text { Theory development: analytical framework } \\
\text { Case study: Standardization of ES in the U.S. Federal Government }\end{array}$ & $\mathrm{BO}$ \\
\hline & Opdam et al. (2015) & $\begin{array}{l}\text { Theory development: analytical framework } \\
\text { Case studies: three Dutch GI planning processes }\end{array}$ & $\mathrm{BO}$ \\
\hline
\end{tabular}

concepts whose plasticity allows "different meanings in different social worlds," while their structure is robust "enough to more than one world to make them recognizable" (Star and Griesemer 1989, p. 393). Similarly, contested concepts represent varying definitions and are linked to different opinions on how to interpret them in practice, but share core ideas (Jacobs 2011, p. 26). The term fuzzy concept builds on fuzzy logic, a mathematic approach developed by Zadeh in the 1960s for dealing with information that is "uncertain, imprecise, vague, partially true, or without sharp boundaries" and which cannot be translated into binary values (Singh et al. 2013, p. 1). According to Markusen (1999, p. 870), fuzzy concepts lack "conceptual clarity" and are "difficult to operationalize."

Several papers researching use of GI, ES, and NBS have applied one of these three theoretical concepts, several of which aimed to reduce the terms' fuzziness (see Table 1). Two examples discuss fuzziness and its implications for planning, including how fuzziness might support or hinder the uptake of novel approaches. Two additional papers developed analytical frameworks to aide transdisciplinary processes around boundary objects, providing the theoretical foundations for this paper.

Of the three concepts, boundary objects have the most elaborated theoretical foundation. For analyzing and potentially also steering concept development processes, Steger et al. created a life cycle for boundary objects from ill-structured to standards and infrastructure, against the backdrop of work by Star (2010) and others (for details, see Steger et al. (2018, pp. 155-156). According to Star (2010, pp. 613-615), standardization is a process to reduce vagueness and flexibility in favor of a higher degree of certainty and applicability. Star and her co-authors also provided a typology of boundary objects and emphasized that boundary objects can take different forms, such as concepts, tools, or infrastructure (as summarized in Star 2010; also Star and Ruhleder 1996, p. 111). Steger et al. (2018, p. 155) use "ecosystem services" as an example for a boundary object that can be considered as both a concept and a product (i.e., a tool for mapping). As we, in this paper, analyze both the processes and the products that evolved in the three cases of GI planning (i.e., representation of concepts in words and illustrations or plans), we use "concept development process" and "product" instead of "object." The content of the concepts usually contains several elements, including definitions, objectives or principles. We will refer to those elements as "concept components." Additionally, we avoid the negative connotation of "contested" and consider "fuzzy concepts" as an umbrella term that is easy to understand, is relatively loosely defined, and can encompass elements of theory related to all three concepts.

\subsubsection{Properties of fuzzy concepts}

Fuzziness is often considered as a temporary stage in the emergence of concepts and attributed with positive and negative impacts. A downside of applying vague concepts is that different meanings can lead to confusion and misunderstanding (e.g., Brand and Jax 2007, p. 23; Markusen 1999, p. 870; Wright 2011, p. 1012). They may be laden with different normative meanings, which are not understood or shared by all stakeholders (e.g., Sussams et al. 2015, p. 188; Wright 2011, p. 1015). Moreover, vagueness might give a false sense of common ground and permit different stakeholders to seize the concept to justify their personal interests (e.g., Brand and Jax 2007, p. 23; Davoudi et al. 2012, p. 305; Garmendia et al. 2016, p. 316). If remaining in a state of fuzziness, concepts may become "an empty signifier which can be filled to justify almost any ends" (Porter and Davoudi 2012, p. 329). 
Fig. 1 Analytical model for a discursive concept development process: For spatial planning, fuzzy concepts develop from discussion and framing within a certain community (Phase 1); to a stage of standardization with inclusion or exclusion of residuals (Phase 2); and will finally be operationalized, usually resulting in a formalized product (Phase 3) (based on (Steger et al. 2018) and (Star 2010)). Different aspects (beveled beams) decrease or increase during the process

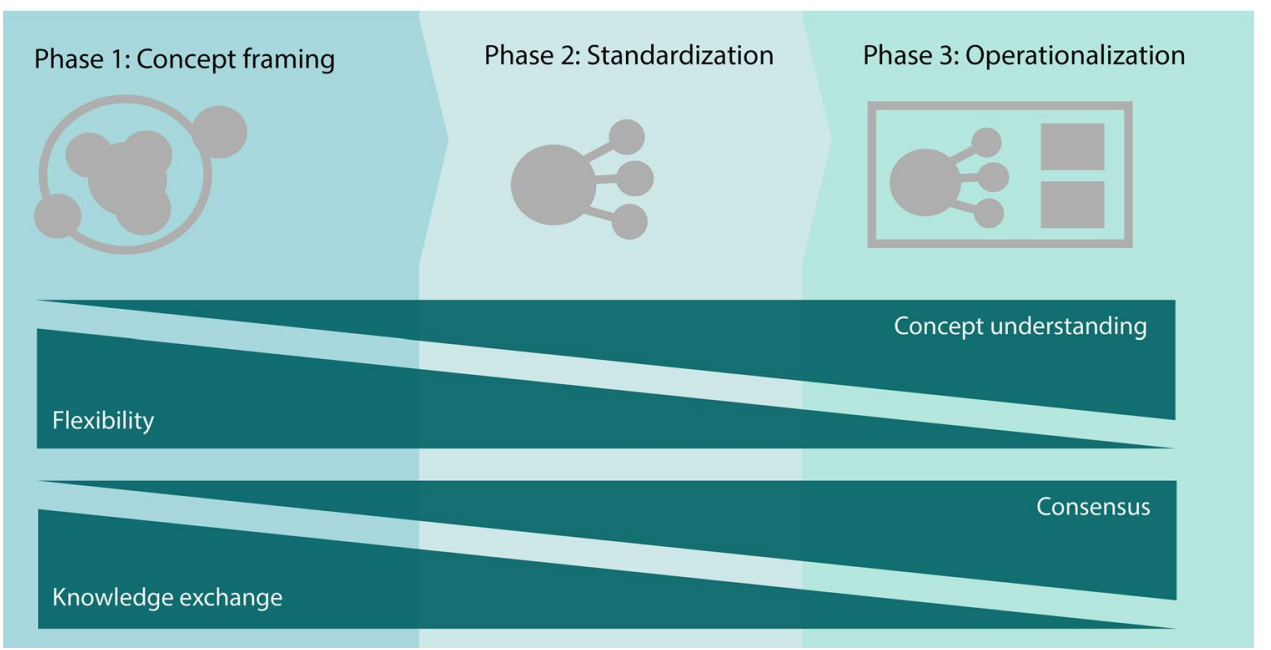

On the upside, the same properties of fuzziness are considered as "interpretative flexibility" (Star 2010, p. 602 based on Star and Griesemer 1989) and as bearing potential to deliberately stimulate discourses (Westerink et al. 2013; Markusen 1999, p. 871). Flexibility might allow modification to local, organizational, and changing circumstances (Star 2010, p. 602; Opdam et al. 2013, p. 1442; Turnhout 2009, p. 409). In terms of knowledge transfer, fuzziness could be used to facilitate exchange not only between different actors "on the same page," but also between actors without consensus, a shared knowledge base, experience, interests, and values, helping them to define common ground (Star 2010, p. 602; Star and Griesemer 1989, p. 393; Opdam et al. 2015, pp. 72-73).

\subsubsection{An analytical model for concept development processes}

With this study, we aim to analyze the life cycle of GI from a fuzzy concept to a final product in different contexts and knowledge exchange processes. Other than Steger et al. (2018, p. 155), who points to the role of specific stakeholders in power, such as regulators or administrators, we aim for a model process that involves stakeholders from different arenas. Hence, we adapt the model introduced by Star (2010, pp. 613-614) and further developed by Steger et al. (2018, pp. 155-156) for transdisciplinary concept development processes in planning:

In Phase 1 "concept framing," an ideal-typical concept development process starts with an exchange of ideas about the meaning of the fuzzy concept among a group of stakeholders who might enter the process with their own understanding (Steger et al. 2018, p. 155). In Phase 2 "standardization", an agreement about concept components and definitions needs to be reached (Steger et al.
2018, p. 155). This also leads to the exclusion of "residual categories," i.e., terms and ideas which might result in new concepts (Star 2010, pp. 613-615; Steger et al. 2018, pp. 155-156). We will focus on the primary concept, and therefore on the standardization, and leave out the point of residuals. In Phase 3 "operationalization", the process results in an operational product (or infrastructure in Star 2010, pp. 611-612) that formalizes how the concept can be applied in a spatial planning context, such as a guideline, policy, or plan.

As these phases are ideal-typical, it can be assumed that in real-world applications, phases overlap or blur into each other. Such processes might occur in different arenas and for different planning levels, for example on a transnational or national level, resulting in knowledge products for planning communities or high-level spatial policies, or on a local level, resulting in spatial plans and policies.

Considering the potential advantages and disadvantages of fuzzy concepts mentioned above, we hypothesize that during such a concept development process, different decisive aspects increase or decrease at different stages (s. Fig. 1):

To utilize a fuzzy concept without eliciting confusion or emptiness, concept understanding needs to be shaped in a way that the concept bears meaning for the relevant stakeholders. The concept should represent common ideas that help to communicate the concept as well as differentiate it, i.e., represent differences or novelty compared to related concepts that are already established in planning (Opdam et al. 2015, p. 64; Lennon 2014, p. 14). The level of shared understanding will be low in the beginning, but will increase over time when the participants share their perspectives and come to a consensus (Steger et al. 2018, pp. 155).

In the initial stage, such an understanding can only be aimed for, if interpretative flexibility (Star 2010, p. 602 based on Star and Griesemer 1989) is allowed without all objectives 


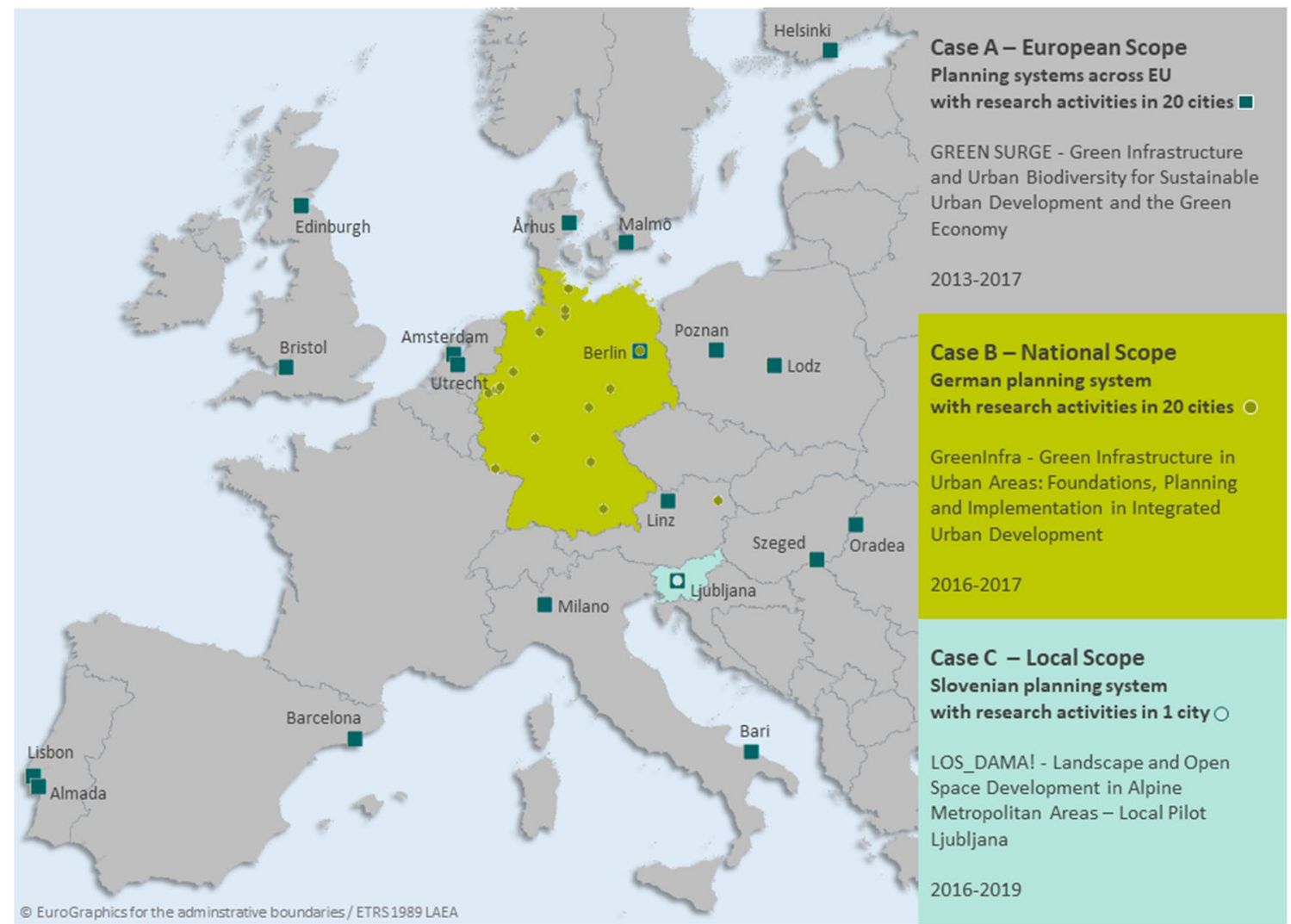

Fig. 2 Geographic scope and basic information of the three case studies, including cities that participated in the research processes

or concept components being pre-set. Flexibility is important for adaptation to stakeholder's perspectives as well as to given contexts and circumstances. However, flexibility will decrease during the process of standardization (Star 2010, pp. 613-614).

The discursive potential of a fuzzy concept can only be tapped if relevant stakeholders are brought together for knowledge exchange, including values and perspectives (Opdam et al. 2015, p. 70). We assume that the need for knowledge exchange is high in the beginning, but will decrease over time given that different stakeholders' perspectives have been taken up in the discourse.

A concept development process can only be considered successful if the process results in a basic consensus that will be accepted and shared by relevant stakeholders and applied, i.e., adopted in local planning processes (Wright 2011, p. 1012; Steger et al. 2018, pp. 156). Consensus might mean that stakeholders support the global idea, but still disagree on specific aspects (Opdam et al. 2015, p. 70).

\subsection{Methodological approach for reflection on green infrastructure research projects}

We aim to examine how concept development processes evolve in different planning arenas. In these transdisciplinary discourses, researchers, governmental, and non-governmental actors with different perspectives and experiences participated in establishing a context-specific understanding of GI. We used the analytical model in Fig. 1 to review processes and outcomes of concept development in three GI projects within Europe. The aim was to identify similarities and differences that might help to understand how such processes can be steered in such a way that the advantages of fuzzy concepts can be tapped and the disadvantages reduced.

We chose three projects for cross-case comparison via literal replication (Yin 2010). All three cases concern the definition and operationalization of the GI concept and build upon each other. Yet, they took place within different contexts: (a) a pan-European research project-GREEN 
Table 2 Stakeholder involvement activities and documentation on the concept development processes for all three cases

Case A Stakeholder involvement

Consultation with stakeholders from 20 cities; 2 public international workshops, 2 internal international workshops, 3 local workshops in Urban Learning Lab cities (in total about 180 participants)

\section{Documents}

Intermediate GI concept drafts included Davies et al. (2015) and Hansen et al. (2016)

Internal minutes and/or recordings for seven stakeholder events (unpublished)

Official reports on stakeholder events (GREEN SURGE Milestone Reports 35, 36, 37—no longer available online)

Intermediate product and GI concept: Urban Green Infrastructure Planning Guide-Field Test Version shared with participating stakeholders (unpublished)

Synthesis of stakeholder reviews of Field Test Version (unpublished)

Final product and GI concept: Urban Green Infrastructure Planning. A Guide for Practitioners (Hansen et al. 2017a)

Case B Stakeholder involvement

Consultation with stakeholders from 20 cities; 3 workshops (in total about 70 participants)

Documents (in German, if not mentioned otherwise)

Intermediate GI concept drafts shared during different stakeholder workshops (unpublished)

Internal reports for two stakeholder events (shared with participants, but unpublished)

Official report on one stakeholder event ("Workshop: Urbane grüne Infrastruktur aus Perspektive der Kommunen" available at www. bfn.de)

Intermediate product and GI concept: Draft version of final product shared with participating stakeholders (unpublished)

Synthesis of stakeholder reviews (unpublished) and researchers' responses to reviews (shared with stakeholders, but unpublished)

Scientific report summarizing results (Hansen et al. 2018)

Final product and GI concept: URBAN GREEN INFRASTRUCTURE. A foundation of attractive and sustainable cities. Pointers for municipal practice-available in English or German (Hansen et al. 2017b)

Case C Stakeholder involvement

Discussions with project partners and Slovenian planning experts; informal meetings and interviews with key local actors; 1 workshop with Slovenian planning experts; 1 workshop with local actors (in total about 70 participants)

Documents (in English and/or Slovenian)

Internal introductory presentation on the GI concept (van Lierop 2017) (unpublished)

Proceedings of the LOS_DAMA! meetings (partly available at www.alpine-space.eu/projects/los_dama/en/home)

Proceedings of the LOS_DAMA! Workshops PA1 and PA2 (UIRS 2019; Typescript)

LOS_DAMA! Compendium. Green infrastructure for better living (Drasdo et al. 2019) (available at www.alpine-space.eu/projects/los_ dama/en/home)

LOS_DAMA! Toolbox. Green infrastructure for better living by (van Lierop et al. (2020) (available at www.alpine-space.eu/projects/ los_dama/en/home)

LOS_DAMA! Synthesis report by van Lierop et al. (2020) (available at www.alpine-space.eu/projects/los_dama/en/home)

Final product: Recreational GI Plan for the Ljubljana Marsh Nature Park (UIRS 2019)

SURGE, (b) a national research project in Germany-GreenInfra, and (c) a local case for the Ljubljana region as part of a European cooperation project-LOS_DAMA! (see Fig. 2). All three projects resulted in a final product, such as planning guidelines or a spatial plan, which included the GI final concept definition plus additional information for operationalization.

All three brought stakeholders from science, ${ }^{2}$ policy, and planning together to define and operationalize the GI concept for the specific context, which to varying degrees can be considered as following a transdisciplinary approach as defined by Tress et al. (2005, p. 488). Bringing stakeholders with different perspectives together with the aim to discuss a fuzzy concept such as GI sparked impromptu knowledge

\footnotetext{
${ }^{2}$ Some project partners have multiple roles, such as being planners and researchers. However, if their activity during the projects was research, we considered them only as science stakeholders.
}

exchange on the nature of GI as they discussed each other's viewpoints. It should be noted that these projects started with a positive take on GI, assuming that it is a beneficial and relevant concept as promoted by European policy as well as European and national research programs (e.g., European Commission 2013). Also, the stakeholders usually became involved due to an interest in or even positive bias towards GI or other aspects of the research projects.

All authors of this paper were actively involved in one or more of the cases analyzed. The evaluation was ex-post: The cases were not specifically designed to analyze transdisciplinary knowledge creation. The documentation is largely focused on the outcome of exchange between stakeholders, i.e., consensus found, and not on individual perspectives. For each case, between 70 and 180 stakeholders were involved in activities. Following (Opdam et al. 2015, pp. 66-67), we used our own recollections to reflect upon the process phases and aspects from the analytical model supported by minutes, reports, and other documents (see Table 2). 
To ensure a balanced perspective for each case, at least three of the authors were involved in the project and contributed their perspectives. In an iterative approach, each case was described as a narrative with the aim to summarize processes into a coherent story and allow extensive understanding. Authors that had been involved in each respective case wrote down their observations for the three concept development phases, including involved stakeholders, discursive approaches, and outcomes. Two of the authors used the narratives to illustrate the discursive processes and distill similarities and differences (see Fig. 3). Based on the narratives, the two authors compared each case against the others and identified open questions. After discussing open questions with the responsible researchers, the narratives were condensed to the information in relation to the four beforementioned aspects most specific for each case and for each of the phases. Finally, the involved researchers reviewed the condensed narratives for appropriate representation of their understanding of their case.

\section{Green infrastructure concept development in three European research projects}

\subsection{Case A: GREEN SURGE}

\subsubsection{Context and involved stakeholders}

Case A, GREEN SURGE, was the first pan-European research project focusing on urban GI planning and implementation. One of the project's aims was to develop an applicable GI concept for urban planning in European cities with different biogeographic, legislative, socio-economic, and cultural contexts. The following focuses on its work package 5 "Green infrastructure planning and implementation." At the project start, the European GI-Strategy (European Commission 2013) had not yet been published and only a few technical reports from the Commission were available, with limited references to urban areas. ${ }^{3}$ In the European, English-language academic literature, the discourse was focused on GI planning in the UK (e.g., Kambites and Owen 2006; Wright 2011), while it was uncertain to which degree GI discourses could be found in other languages. As later investigated in the GREEN SURGE project, the GI concept had been adopted in the UK and a few cities in mainland Europe (Davies et al. 2015, p. 37).

The concept development process was strongly driven by the funded research partners, who represented 14

\footnotetext{
3 For an overview of these reports and studies see https://ec.europa. eu/environment/nature/ecosystems/studies/index_en.htm.
}

organizations in 11 European countries. Around 60 researchers contributed to the investigation of planning realities in 18 countries resp. 20 cities in which they were familiar with the language and/or context. About half of these researchers also engaged in discussing the GI concept during the different process stages, bringing their experiences with their investigated cases into the discussion. Planning stakeholders in five cities acted as voluntary partners in so-called Urban Learning Labs. Planning stakeholders from 15 additional cities were consulted at different stages. These stakeholders were primarily representatives from municipal planning departments, but a few were from NGOs, consultancies, or the policy sector. Some received travel funding for attending project events. Additional stakeholders from planning and policy practice were engaged on a voluntary level at two public workshops, where they provided feedback.

\subsubsection{Concept framing}

The concept development process started with a literature review on GI, resulting in a relatively broad spectrum of planning aims and principles and a basic definition of GI that mirrors the general definition of the abovementioned European GI Strategy ("interconnected network of green spaces, which together deliver ecosystem benefits to society" in Davies et al. 2015, p. 8; Table 3 and 4 in "Appendix"). To gain knowledge about different planning realities in Europe, the current state of green space planning was investigated in the 20 participating cities via interviews involving 43 representatives from local and regional planning authorities and a (planning) document analysis (Davies et al. 2015). The research team discussed the results during an internal workshop (see Fig. 3, Part A) where each of the initial concept components was evaluated against the planning realities and the potential added value for planning in those cities. When discussing the different concept components, it became evident that they were partly vague (e.g., spatial connectivity vs. connectivity of actors) or interlinked (e.g., participatory planning and transdisciplinary GI development). Thus, there was a need for excluding overlapping components and for a clearer understanding of the remaining components.

\subsubsection{Standardization}

During the internal workshop, the researchers agreed on a reduced number of distinct planning aims (such as biodiversity protection; first described as "policy objectives," later as "urban challenges") and core GI principles deemed most relevant and not redundant (Fig. 4; Table 3 in "Appendix"). A focused literature review and interviews with stakeholders involved in 16 different GI projects from the 20 cities were used to make the concept components more tangible and identify important aspects for operationalization. This 


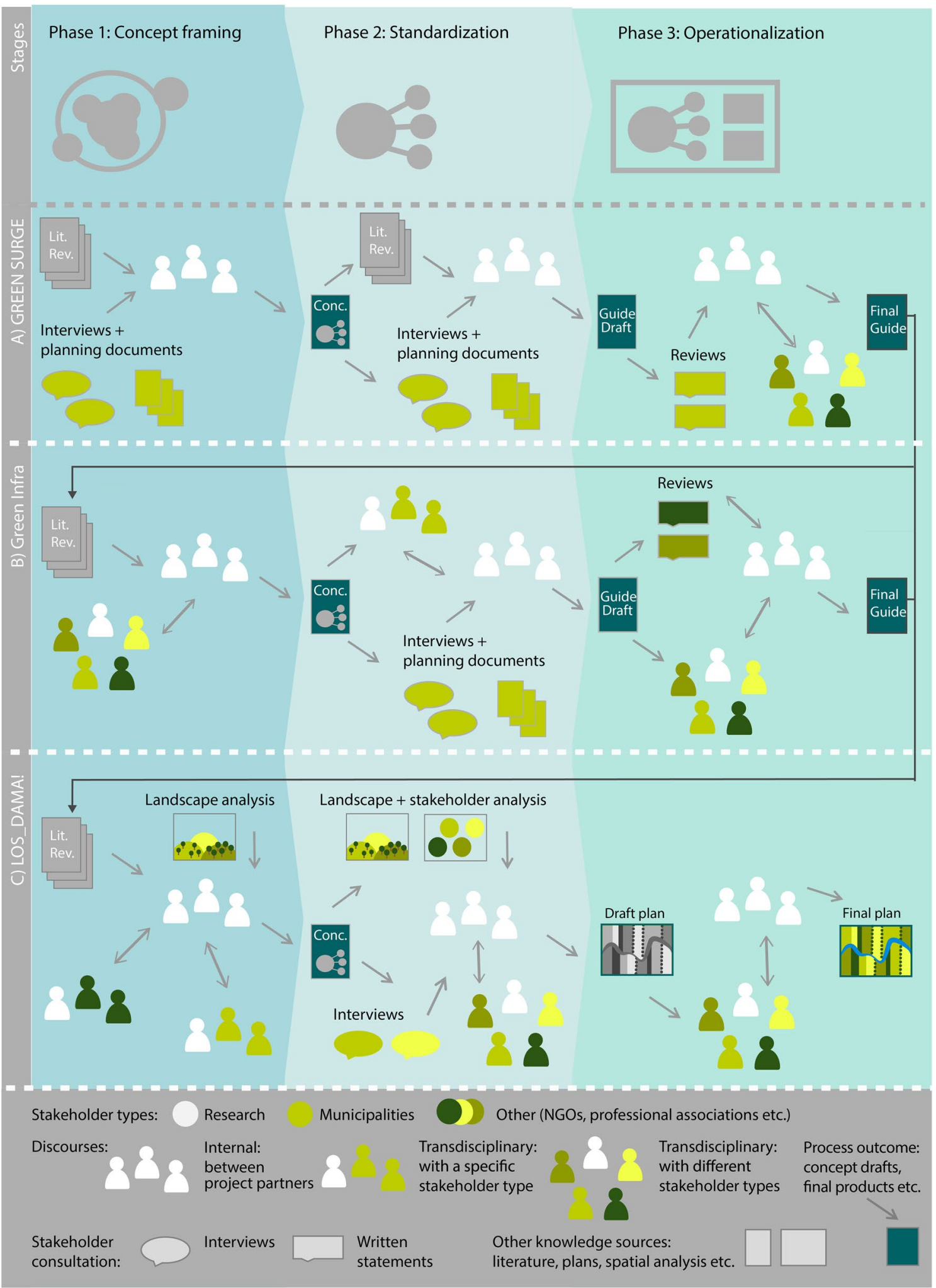

Fig. 3 Simplified overview of the concept development processes and resulting products in the three cases (concepts, guides or plan and their drafts), including different forms of knowledge gathering and exchange such as literature reviews, spatial analysis, internal and external discussion, and stakeholder consultation. Number of symbols does not represent the actual number of activities (e.g., interviews). Lit. Rev. means literature review and Conc. means concept 
Fig. 4 Conceptual scheme illustrating basic components of urban green infrastructure planning developed in Case A (courtesy of GREEN SURGE, published in (Hansen et al. 2017a)

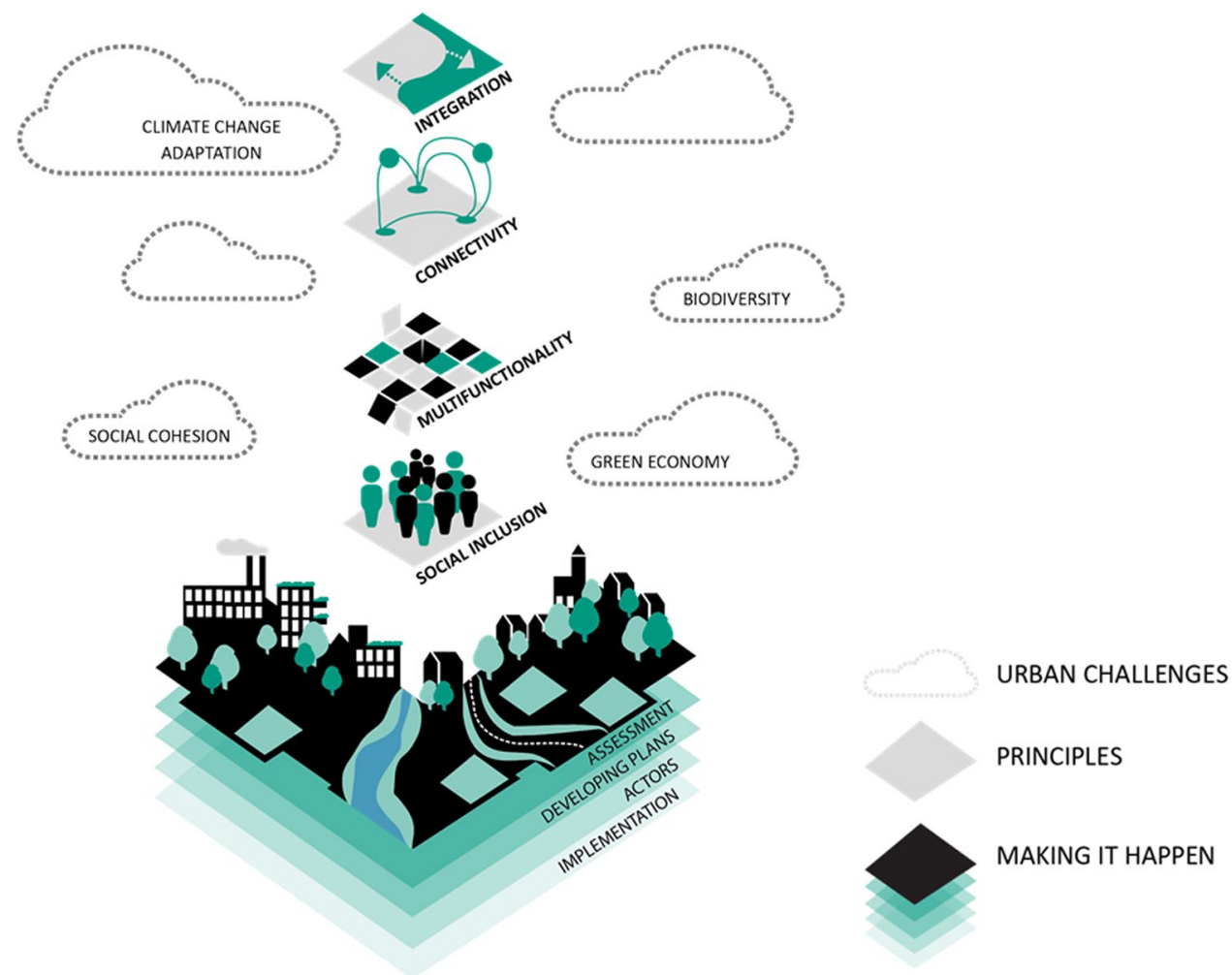

resulted in detailed description of each concept component, usually including a number of sub-concepts (e.g., for biodiversity: protection of species diversity, native biodiversity, and/or rare species), and complemented with two good practice examples of implementation in planning (Hansen et al. 2016). Both knowledge from the literature and the stakeholder perspectives helped to combine recent (academic) knowledge with practical considerations. In this phase, a detailed definition of GI was developed by the responsible researchers referring to the refined concept components (i.e., GI principles; see Table 4 in "Appendix").

\subsubsection{Operationalization}

In the operationalization phase, the refined concept and good practice results were developed into a preliminary planning guide, which planners from the 20 cities were invited to review. Seven individual feedbacks and one coordinated feedback by several planners from one city were received. The level of detail varied, ranging from general statements to detailed suggestions. Stakeholders in one of Urban Learning Lab cities carefully reviewed the document to get inspiration for their own green infrastructure plan in development and provided detailed feedback. The GI concept and guide were further discussed in seven events, involving experts from different sectors of local governments (city and city-region), research institutes und universities, NGOs, consultants, and the European
Commission and that ranged from small discussion rounds in one municipality to international public events with over 40 participants. Most stakeholders were content with the developed GI concept and considered it as innovative. For specific components of the concept, such as the aims, some stakeholders opted for different priorities (e.g., human well-being and health), others perceived good practice examples as more or less innovative (e.g., some cities already use green spaces for storm water management, for others this was new). In this phase, the research project was in its final year and knowledge had been generated according to the urban challenges and planning principles selected in prior phases. Consequently, major changes to the concept were not feasible. However, in accordance with the feedback and in acknowledgement of different planning realities, adaptability and flexibility of the GI concept were highlighted in the final guide as follows:

- integration of universal elements of planning processes, such as "assessment" or "actors" not tailored to a specific planning system (see Fig. 4),

- empty symbols ("clouds") for urban challenges in the conceptual scheme to indicate openness,

- good practice examples with contextual factors to make differences visible,

- modular structure so that all parts can be read individually to allow focus on topics of interest. 
The exchange with stakeholders further helped to fine-tune recommendations for municipal planning, such as more knowledge exchange and cooperation. For example, "networking, forming partnerships between different departments and sectors and integrating (external) experts early on" is a core recommendation within the planning guide (Hansen et al. 2017a, p. 52). In response to the stakeholders' request to keep all results lean, the concept definition was shortened with a focus on core concept components and written in simple and concise language (see Table 4 in "Appendix"). Overall, the iterative exchange with different stakeholder groups did not significantly impact the GI concept or the content of the guide, but did influence how the concept and recommendations for application were described and structured (see Hansen et al. 2017a).

\subsection{Case B: GreenInfra}

\subsubsection{Context and involved stakeholders}

Case B, GreenInfra aimed at operationalizing the GI concept for German cities. The project started when awareness of the concept was just rising and being considered at the national policy level (Kahl and Gehrcke-Schleithoff 2016). In Germany, the spatial planning system is well-established and institutionalized including environmental resp. landscape planning. Additionally, Germany has witnessed an upswing in strategic planning, which enables the uptake of new concepts and perspectives (Mell et al. 2017, pp. 5-9). The GI concept was largely unknown, but planners thought it could advance planning and planning communication (Albert and Haaren 2014, pp. 5-6). Parallel to GreenInfra, a "Federal Green Infrastructure Concept," which bundles plans and data on landscape planning and nature conservation for the national level, and national strategies to promote urban greening, for example, the "White Paper: Green Spaces in the City," were developed (German Federal Agency for Nature Conservation 2017; Federal Ministry for the Environment, Nature Conservation, Building and Nuclear Safety 2018, see also Mell et al. 2017, p. 9). Knowledge generated in GreenInfra contributed to these processes by sharing expert statements and intermediate results, e.g., in the part of the Federal Concept on urban areas (German Federal Agency for Nature Conservation 2017, pp. 38-41).

The stakeholder groups dominant in the concept development process were the funded research partners and the national policy representatives from the funding agency and ministry. Compared to Case A, the research team was small, involving about 10 persons from two universities and one consultancy firm. Stakeholders from science, policy, and planning practice, including professional associations and NGOs, were invited to join an expert panel, which met twice for workshops with about 25 participants each, once during the concept framing and once during the operationalization (see Fig. 3, part B). Participants were selected to represent diverse professional perspectives, including conservation and ecology, landscape architecture and recreation, and urban planning, as well as to include relevant NGOs, professional and political associations. In addition, a 2-day practice workshop with 20 representatives from 13 cities took place during the standardization phase. Travel subsidies were offered for participation in all events.

\subsubsection{Concept framing}

In the first phase of Case B, Case A's aims and principles were reviewed in light of the national literature (see Fig. 3, Part B). At the first workshop with the expert panel, the preliminary GI concept was initially contested with regard to the priorities for GI, which differed between shrinking (focusing resources on most important GI elements) and growing cities (creation of more accessible GI). Moreover, nature conservationists wanted to focus on ecological aspects, while landscape architects emphasized cultural aspects, including spatial design and aesthetics. Participants wanted to protect the concept from being misused by making it very specific, but there were also concerns about a too narrow definition that would, for example, prioritize ecological values over social ones.

\subsubsection{Standardization}

During the workshop, core concept components were defined, resulting in a comprehensive GI approach in accordance with the broad variety of needs of the involved stakeholders. Priorities were also discussed and agreed upon (i.e., "health and well-being" is mentioned first and "economic development" last, representing relative importance). Most aims also include more than one key term (e.g., "climate change adaptation and resilience"). Instead of excluding principles, the stakeholder involvement led to supplementing the GI principles from Case A (with slightly different wording) with "improve open space quality" to emphasize maintenance and enhancement of existing GI (see Table 5 in "Appendix"). The four aims in Case A were supplemented with three additional aims (see "Objectives" in Fig. 5).

To investigate means for implementing the developed GI approach, 20 good practice cases were analyzed through desk study and telephone interviews. The cases represented a variety of formal and informal planning instruments and differed with regard to population size, region, and socioeconomic conditions to capture the diversity of German cities (Hansen et al. 2019, Chap. 5). Additionally, municipal representatives from those cities were involved in the practice workshop to discuss innovation potentials and implementation challenges. This knowledge exchange was used 


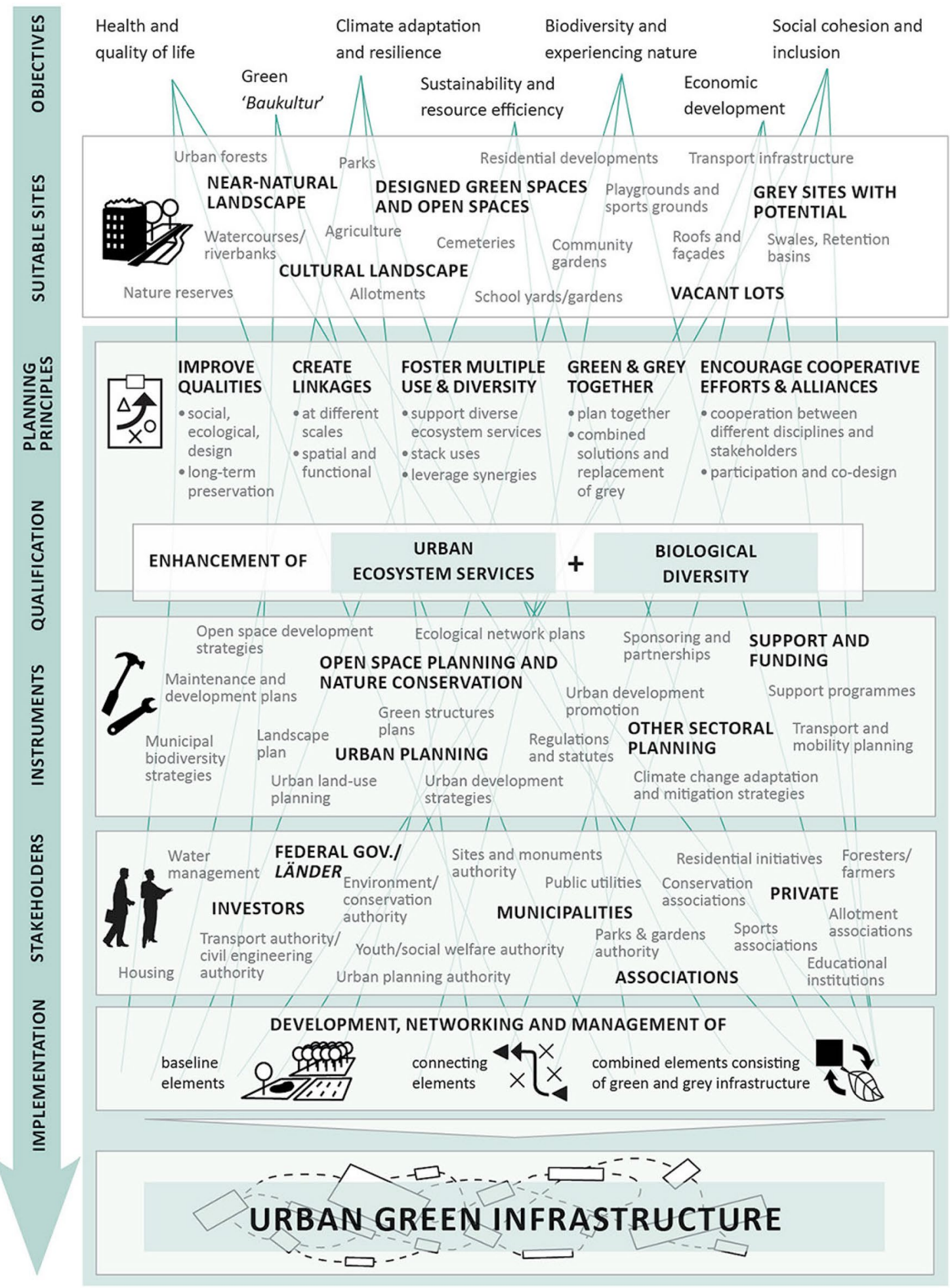

Fig. 5 Conceptual scheme illustrating basic components of urban green infrastructure planning developed in Case B tailored for the German urban planning system (courtesy of BfN, published in (Hansen et al. 2017b))

by the research team to scrutinize how the developed GI concept could help with the needs and challenges of German cities. This exchange confirmed the need to keep the concept flexible and multifaceted so that different stakeholders could identify with it. In addition, the workshop helped to collect 
practical examples on and evaluate different existing planning instruments for implementing GI.

\subsubsection{Operationalization}

In the third phase, the gained knowledge was synthesized into a draft guide on the GI concept. The draft was discussed in detail in a second workshop with the expert panel to identify improvements. After improving the draft, the stakeholders were invited to review the full document. Nine experts provided their opinions, including preferences for title alternatives and suggestions to stronger emphasize the benefits of GI. A few suggestions were rejected due to conflict with prior decisions, such as a stronger focus on selected stakeholders. Overall, in this phase, no major objections or requests for changes were articulated by the stakeholders, even though different professional perspectives were still evident by relative importance or preference for certain aims or principles or other concept components. Decisions on the final GI concept were made after weighing the arguments between the research team and the funding agency and explained to the stakeholders during the final review process.

To represent the diverse needs of German cities, the final conceptual GI scheme illustrates the diversity of options, for example, regarding green space types, actors and instruments (see Fig. 5). Corresponding to the detailed conceptual illustration, the final definition of the concept was also relatively complex. It starts with a definition similar to that of the European GI Strategy and refers additionally to normative goals for GI, its contribution to societal challenges, and the diversity of involved stakeholders (see Table 4 in "Appendix").

The guide about the concept and its implementation was published by the involved Federal Agency of Nature Conservation and the related Environmental Ministry and was officially supported by five national associations and NGOs for green space planning, landscape architecture, nature conservation and biodiversity protection (Hansen et al. 2017b). This high-profile consensus was additionally formalized via endorsement from these organizations in the final documents. While the guide is targeted at the municipal policy level, implications for the federal and national policy level were published in a separate report (Hansen et al. 2019).

\subsection{Case C: LOS DAMA!}

\subsubsection{Context and involved stakeholders}

Case C, LOS_DAMA! aimed to test and develop tools for (non-statutory) GI planning and management in peri-urban landscapes in Alpine city regions (van Lierop et al. 2019). As one of the seven local pilot projects, the Urban Planning Institute of Slovenia (UIRS) developed and tested the GI approach in the Ljubljana Marsh Nature Park area, Slovenia's largest protected wetland. The park increasingly attracts recreational visitors due to its natural and cultural qualities and proximity to the city. The area is governed on a national level by park administration, but on a local level by seven municipalities (Drasdo et al. 2019).

At the start of the project, GI was not established in Slovenian planning, although other comprehensive landscape planning approaches have been implemented successfully at different levels. Experts from Slovenian planning institutions, however, were already familiar with GI through other EU-funded projects and plans to introduce GI in new national and regional planning policies were being discussed. The application of the GI approach therefore also served to test GI's compatibility for Slovenian planning practice.

The UIRS team of 6 professionals initiated the concept development process by framing different perspectives on GI and possibilities for its application through informal meetings and discussions with key local actors, regional and national policymakers as well as LOS_DAMA! partners. Through interviews, UIRS discussed the GI concept further with more local stakeholders from municipalities, park management, and NGOs. Members of these organizations also participated in a collaborative workshop to identify potentials and conflicts for GI for recreation and tourism (approx. 20 participants). In the first step to operationalization, UIRS developed a draft thematic GI plan. This plan and its potentials for implementation were discussed in another workshop, which brought together 30 stakeholders from different disciplinary backgrounds (see Fig. 3, part C). All stakeholders contributed to the progress on a voluntary basis, with several stakeholders attending out of personal or professional interest.

\subsubsection{Concept framing}

In the initial phase, experiences from open space planning in Slovenia and knowledge on GI gained from Case $\mathrm{A}$ and $\mathrm{B}$ as well as other literature was discussed with stakeholders from LOS_DAMA! and Slovenian national and regional planning authorities (see Fig. 3, Part C). One LOS_DAMA! meeting, aimed at identifying spatial GI components and the benefits they provide, sparked a discussion on what constitutes GI and how it can be determined. In addition, UIRS conducted a comprehensive spatial analysis and held a range of meetings with key stakeholders (e.g., municipalities, park management) to discuss land use conflicts within the Nature Park as well as potential solutions. Based on these actions, different possibilities for understanding and integrating GI in the planning context were internally examined and discussed by UIRS. The usual comprehensive GI concept was 
considered too broad by UIRS to sufficiently address the issues in the case study and to determine possible spatial GI components of this natural landscape as well as too fuzzy for local stakeholders to understand. This challenged UIRS to question the GI approach and develop a suitable approach for the case study.

\subsubsection{Standardization}

The project team addressed the perceived fuzziness of the GI concept with a new thematic focus aiming to enable and support tourism and recreation. Other GI aims, as in case A and B, were not rejected but became secondary. Through a stakeholder and spatial analysis concentrating on recreation and tourism potentials along with other land uses, synergies and conflicts between diverse functions and actors could be identified. Through an internal brainstorm session, the project team then developed first ideas for a draft multifunctional GI network. With members of municipal offices, park management, tourist agencies, and NGOs, selected based on the stakeholder analysis or via personal contacts in the area, ideas on GI, including on connectivity and multifunctionality, were discussed in interviews and in smaller mixed groups in a workshop (approx. 20 participants). Bringing participants with different backgrounds together was crucial to debate and develop new solutions (e.g., the division of different uses at different times in the same area). Municipal stakeholders expressed a more economic focus, which UIRS counterbalanced by broadening the aim to well-being, a healthy lifestyle, recreation, and living quality to ensure the inclusion of the needs of inhabitants and visitors as well as broad consensus. The interviews further refined the definition of GI components within the park area and implementation measures, such as recreational paths.

The thematic focus helped all stakeholders to understand and identify with the concept. In this way, it opened up the discourse and engaged stakeholders who previously were unfamiliar with the GI concept and showed a lack of interest in the project or collaboration. The revised GI concept, developed through analysis of the local potentials for GI, altered the core characteristics of the GI concept used in Cases A and B for a recreational focus. For instance, "balance between development and conservation" substituted the principle "green-grey integration," as it stressed the potential of GI to accommodate other uses, while preserving natural characteristics and values (see Table 4 in "Appendix"). Moreover, accessibility was preferred over a wider perception of social inclusion in the other cases as a GI objective, namely providing access for different users, while "improve open space quality" was replaced with "attractiveness" to emphasize the socio-cultural values of GI.

\subsubsection{Operationalization}

Based on the results of the analyses, the interviews, and the workshop, the project team developed a draft "Recreational GI plan for the Ljubljana Marsh Nature Park" (see Fig. 6). The GI plan was presented in a second workshop with 30 stakeholders, including NGOs, municipal officers from different sectors, national and regional policymakers, a development agency, as well as hunter, fishing and tourist associations. In smaller diverse groups, they discussed the GI plan's implementation challenges and potentials. No opposition to the plan was expressed, and agreement for multiple co-existing uses and activities was reached. Moreover, the GI plan was assessed as an adequate support tool for communication and coordination between different stakeholders, planning levels, and sectors, as it reminded in particular municipal stakeholders that their projects should not end at the municipal border and that other stakeholders should be involved (e.g., farmers, hikers, guides, tour operators). Based on the workshop outcomes, UIRS finalized the Recreational GI plan illustrating a strategic network of multifunctional green corridors supporting nature conservation and sustainable mobility in the Ljubljana Marsh area. The concrete spatial arrangement of the corridors is kept open to allow adaptability to local needs and projects. The plan served as a template to support the incorporation of GI planning proposals into municipal spatial plans and the management plan of the Ljubljana Marsh Nature Park.

\section{Utilizing fuzzy concepts with or for practice}

In our study, we investigated how the GI concept evolved in three different transdisciplinary discourses, using an analytical model with three different phases and four aspects that characterize such concept development processes. In the following, we will discuss the similarities and differences between the three cases and derive recommendations for the deliberate use and steering of processes of fuzzy concept development for bridging planning science, policy, and practice.

\subsection{Reflection on concept development processes}

Each case was transdisciplinary in nature, as researchers interacted with stakeholders from policy and practice as well as from civic society. Stakeholder participation in each involved consultation (i.e., interviews with stakeholders, collection of reviews) and co-creation of knowledge (i.e., discussions rounds or workshops). Despite co-creative 


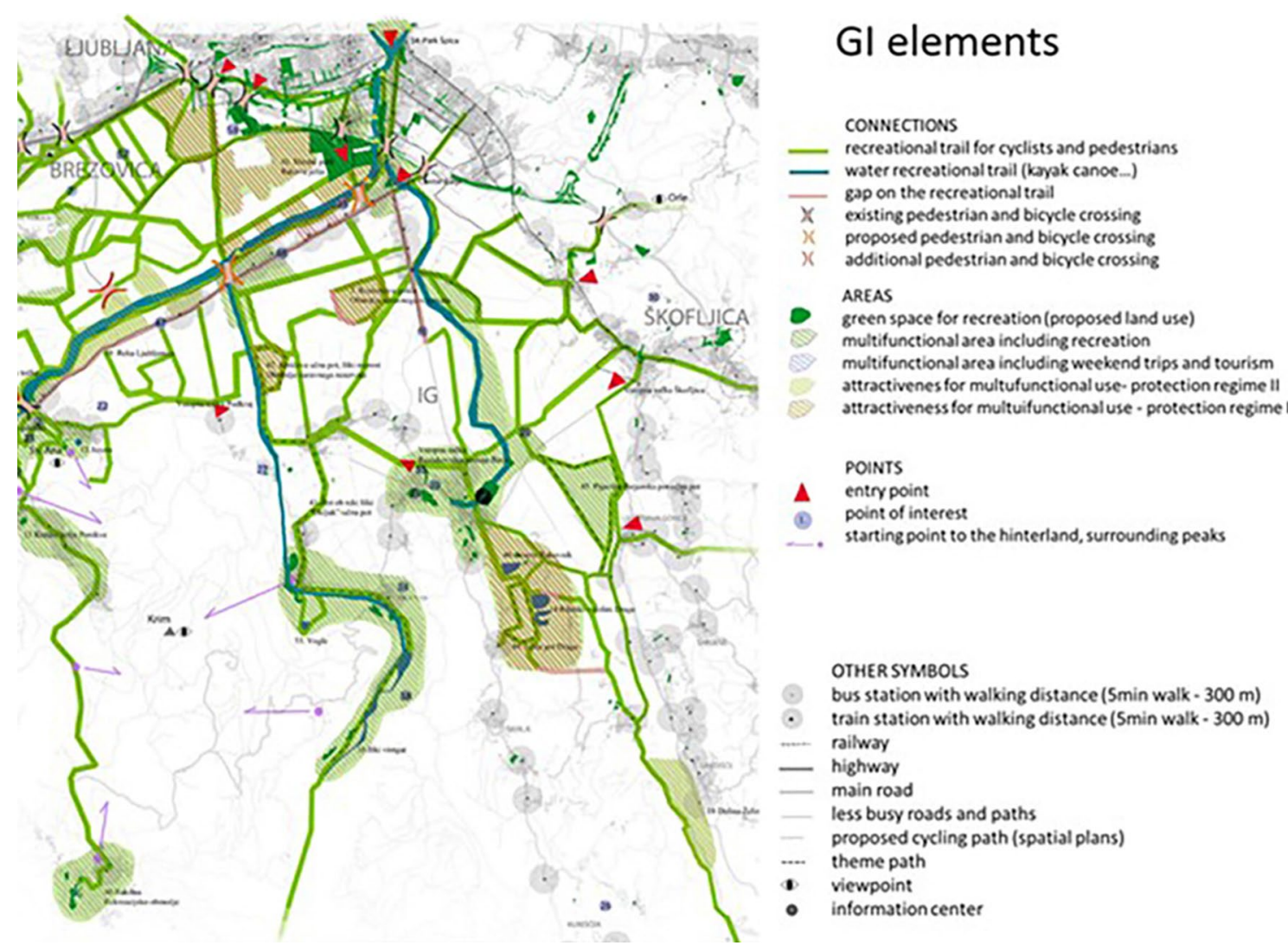

Fig. 6 Map extract for the Recreational GI plan for the Ljubljana Marsh Nature Park, which indicates the recreational trails connecting green areas with different levels of recreational use and areas for multifunctional use (Author: Živa Ravnikar, courtesy of UIRS)

elements in all cases, the decision-making power was with the research consortium (and in Case B also with the funding organizations).

The stakeholder involvement in the three cases can be distinguished by two different approaches: concept development "for practice," with a focus on consultation, and one "with practice," based on discussion and agreement with stakeholders. Due to little means and opportunities to continuously engage with stakeholders from policy and planning (except with selected persons in the Urban Learning Labs), the process in Case A can be mostly specified as "for practice." The limited involvement of the stakeholders from the 20 cities that had been interviewed and later asked for reviews resulted in lower commitment and lack of response compared to those involved in the Urban Learning Labs. Overall, this does not necessarily impede the relevance of the outcomes but limits its formal legitimacy and implementation (Innes and Booher 1999, pp. 415-416).

In contrast, GI was defined "with practice" to a larger extent in Cases B and C. In Case B, stakeholders were officially involved and were recognized in the final product. In Case C, UIRS consulted and collaborated with various stakeholders throughout the project, with many having a professional, economic or personal interest either in the project or the case study area. In the following, we will discuss the advantages and disadvantages of "with" or "for" practice based on our cases and in relation to the analytical model.

\subsubsection{Knowledge exchange remains important in all stages}

In all three cases, the GI concept was used to stimulate knowledge exchange between stakeholders from science, policy, and planning. In contrast to the assumption in our analytical model, knowledge transfer did not decrease across the process. Exchange took place in each phase of the concept development process with different intensities and purposes such as framing the GI concept in the first phase, gathering specific information during the phase of standardization, and finally operationalizing the concept in a way that is attractive and meaningful for practice. In Case C, the knowledge transfer even increased when more stakeholders from a larger variety of backgrounds were involved. The results demonstrate that knowledge exchange and transdisciplinary cooperation are important at all stages and scales for addressing complex urban issues with GI, ES, or NBS 
(Frantzeskaki 2019, p. 107; van der Jagt 2019, pp. 209-210; Luederitz et al. 2015, p. 108).

The discourse on the GI concept "with practice" brought together stakeholders with different perspectives. For instance, in Case B, priorities for GI components were different between nature conservationists and landscape architects. This allowed for those groups to exchange viewpoints and consider both perspectives in the joint concept development. The transdisciplinary exchange helped to exclude, reformulate or add components to the GI concept such as planning principles on open space quality. For Case $\mathrm{C}$, the knowledge transfer brought different stakeholders together who previously had little interaction (e.g., hunters and tourism associations). It resulted in a GI concept which was more meaningful for stakeholders. Such meaningfulness cannot be taken for granted in an approach where the concept definition had been based on concept components identified via scientific literature review (e.g., Monteiro et al. 2020, pp. 8-9; Hansen and Pauleit 2014, p. 517).

In concept development approaches "for practice," knowledge transfer is one way via consultation of stakeholders (e.g., interviews, online consultation, ${ }^{4}$ reviews of concept drafts), which to a certain degree happened in all cases but most strongly in Case A. This approach allows collection of input from a large amount of stakeholders, including the option to group and prioritize these, as demonstrated in Case A with the survey in 20 cities. Yet, once the stakeholders are consulted, the possibility to ask for further elaboration is limited. Another disadvantage is that due to limited exchange, stakeholders might be less interested to contribute, as happened in Case A during the review process. With direct communication between the responsible team and stakeholders as in Case B and C (e.g., discussion groups, round tables, workshop formats), ambiguities in statements can be addressed directly. Yet, as with all participatory processes, there is a danger that vocal and dominant participants might lead to biases.

\subsubsection{Consensus should mark the end of each stage}

In all three cases, it was evident that consensus, or the lack thereof, impacted the concept development process. Counter to the analytical model, opportunities to openly articulate objection or agreement, including means to reach a formal consensus, appeared important at each stage of concept development, not only towards the end (see also Innes and Booher 1999, p. 416). Our study suggests in a process "for practice," consensus can be more easily reached in a relatively small group such as the research team compared to a heterogeneous stakeholder group. However, as shown

\footnotetext{
${ }^{4}$ Here without online discussion boards or other interactive formats.
}

in Case A, a lack of transdisciplinary discourse in an early stage resulted in stakeholders disagreeing with specific aspects at a later stage, a phenomenon that did not occur in the other cases. Legitimacy for stakeholders can be reduced if they were not convinced that the decision-making group represented their experiences, needs, and interests. Likewise, biases might be more dominant in a homogenous group and conflicting views can get ignored instead of being debated.

In the approaches "with practice," the first workshop with stakeholders in Case B framed the GI concept in an early stage and core components were not questioned throughout the later process. In Case C, the GI concept was discussed in each project phase in meetings and workshops with different actors, which resulted in a multi-level conceptual agreement about GI development. It was evident that specific concept components or priorities were decisive for certain groups to accept the concept (i.e., perspective of landscape architects on open space quality in Case B or the balance between conservation and development in Case C).

In the cases "with practice," formal consent was reached. In Case B, this was furthered by naming all involved in publications and having professional organizations and NGOs sign the final GI document. Additionally, the publication of the product by governmental bodies and official support by multipliers from policy and planning gave legitimacy to the German GI concept. In Case C, the workshop with local stakeholders produced no objections to the draft plan, although some doubt or dissent was expected, and resulted in support from municipal stakeholders to incorporate the GI concept in local spatial plans. This does not prove that all involved fully consented with the final concepts, but they nevertheless endorsed them.

\subsubsection{A certain level of interpretative flexibility can be maintained}

The interpretative flexibility of the GI concept helped to bring different stakeholders and disciplines together and adapt the concept to different contexts. Stakeholders dealing with green space planning either from an ecological or from a socio-cultural perspective felt that GI is a relevant concept for both, which was especially evident in Case B. However, a high degree of interpretative flexibility can also be a hindrance, as in Case C, where initially, the GI concept was too broad for the spatial context and for stakeholders. Here, the narrowed focus on recreation brought different stakeholders together.

In the analytical model, it was assumed that (interpretative) flexibility would significantly decrease during concept development. However, in all cases, the GI concept gained a shared understanding, but still maintained elements that could be interpreted differently by involved stakeholder groups. In relation to an approach "with" or "for practice," 
no significant differences were noted for interpretative flexibility. However, in Case A, the GI concept only contained key components and remained on a very general level so that for its application, components could be added or concretized. In Case B, a high number of potentially relevant components were integrated into the GI concept, though flexibility was kept by showing the options for their further application. This was possible as concept development took place within just one planning system, i.e., German, as compared to multiple planning systems in Case A. Therefore, for example, different planning instruments for GI implementation that were known to all participants could be included. The GI concept in Case $\mathrm{C}$ was tailored to a specific landscape area, but still only provided a conceptual and spatial frame that could be adapted during the development of concrete measures. This flexibility fits well to spatial planning, which operates at different levels of concretization and adaptation of measures to fit specific conditions and changing circumstances (Cortekar et al. 2016; van Assche et al. 2020; van der Jagt 2019).

Flexibility can be reduced at an early stage but can also be maintained towards the end of the concept development process, largely depending on the heterogeneity of the context and the stakeholders. An early focus might make the concept operationalization more straightforward. However, it can also lead to a lack of acceptance by stakeholders in a later stage, as they do not find their perspectives and values considered. Homogenous contexts allow narrowing down the concept (e.g., focusing on one issue relevant for the case) or specifying the concept's components. In processes "for practice," less might be known about the stakeholder's needs, which requires openness to integrate a diversity of perspectives. In processes "with practice," concepts can be more easily defined, even when many stakeholders are involved (e.g., many stakeholders can agree upon one issue).

\subsubsection{Joint concept understanding needs to be developed in any new context}

As the cases succeeded and consequently built upon each other, obviously knowledge and experience on how to frame GI as a planning concept accrued. The literature and EUpolicies on GI added to a similar basic understanding of the GI concept (Seiwert and Rößler 2020, pp. 1-2), which primed the researchers and presumably also stakeholders familiar with the literature. Nevertheless, each case had a "fuzzy" start in the phase of concept framing, as available knowledge and potential components of the GI concept were newly discussed. Even if an earlier defined GI concept was applied to start the concept development process, as the GI concept of Case A was used in Case B, the new context and stakeholders forced a restart of the discourse on GI. This indicates that such a process of review, exchange, and agreement is needed for the adaptation of fuzzy concepts in each new context, regardless of how much knowledge has been created elsewhere (Opdam et al. 2015, pp. 72-73).

Each of the discourses in the three cases led to additional or adjusted concept components or different priorities, wording, or graphic representation: The GI concept remained relatively general in Case $\mathrm{A}$, more tailored to the national context in Case B, and focused on a specific theme in Case C. In the approaches "with practice," Case $\mathrm{C}$ was first focused but later resulted in a broader spectrum of planning aims connected to the focal theme by including well-being for people and the environment to counter-balance economically focused objectives. In Case B, stakeholders' perspectives from different disciplines expressed during workshops also contributed to a more holistic concept understanding that balances ecological considerations with socio-cultural aspects. Yet, all resulting GI concepts largely overlap regarding core ideas. The similar outcomes confirm that the GI concept can be adapted to different contexts (e.g., national planning system or local needs) and supplemented with context-specific elements without losing its core meaning (see also Seiwert and Rößler 2020, p. 7).

\subsection{Recommendations for using fuzzy concepts}

For making a fuzzy concept operational, both approaches"for" and "with practice"- appear feasible if in line with the need for legitimacy and if pitfalls and biases are considered. For the first approach, researchers should collect and consider practical knowledge and ensure that they gain a broad perspective on the stakeholders' needs and interests to develop concepts that are relevant and applicable. Methods for doing so from our cases include expert interviews, presentation of intermediate results at conferences for stakeholders, and reviews of written documents by selected stakeholders.

In a concept development process "with practice," methods for discussion with and among stakeholders as well as joint decision-making (i.e., group discussions and votes) need to be employed at all main steps, concluding with a formal procedure for the stakeholders to officially express their support (e.g., by signing a final document together). Time and resources for bringing a representative selection of stakeholders together need to be considered when planning such a process.

Based on the experiences in the three cases, a refined version of our analytical model can provide guidance for a more deliberate steering of such processes (see Fig. 7):

- Concept understanding increases during transdisciplinary concept development processes. However, involvement of new stakeholders or shifts in priorities or perspectives at different process stages might 


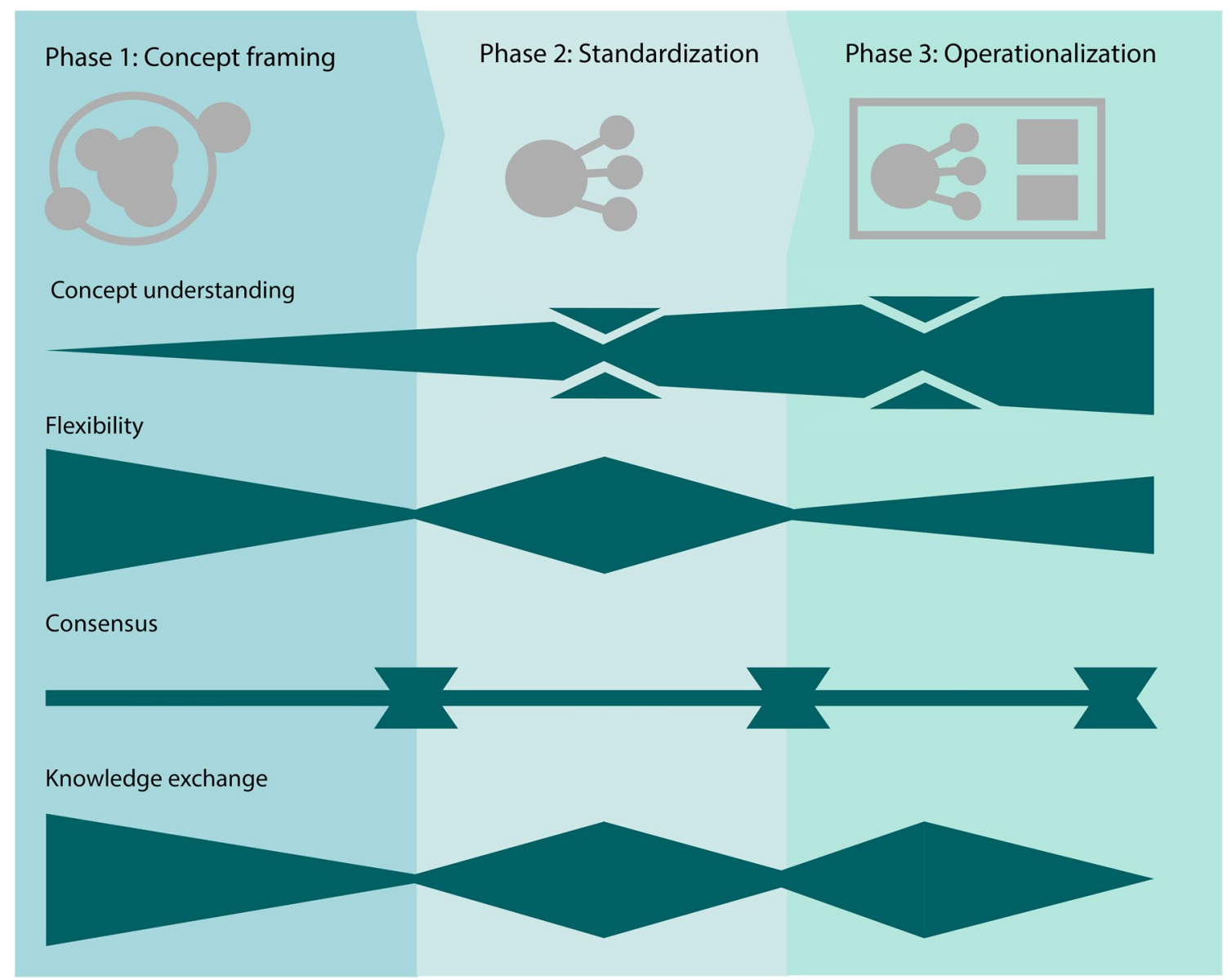

Fig. 7 Adapted model for transdisciplinary concept development processes from fuzzy concept to operationalized approach to planning

challenge the established understanding. It thus needs to be considered if the concept development process would rather benefit from being exposed to different perspectives at different stages or from a stable group of stakeholders that in the end should strongly agree with the concept.

- In every phase, flexibility can be reduced, e.g., by excluding concept components when entering the standardization phase. However, it might be important to maintain an adequate degree of interpretative flexibility that allows uptake of the concept in different contexts and helps diverse stakeholders to agree with the concept. Thus, overall, flexibility might change, i.e., by more clarity about what is considered GI and what is not, but not significantly decrease. Depending on the purpose of the concept, such as bringing different stakeholders together versus creating an operational product (i.e., technical protocol), a higher or lower level of flexibility should be pursued.
- Means to find consensus should mark every phase of the process, ideally involving the relevant stakeholders to ensure that the concepts get further developed in a mutually agreeable manner. Thus, reaching consensus should be considered as milestones for structuring the process.

- The need for knowledge exchange might decrease across the process. Yet, in all phases, input from different stakeholders can help toward operationalization of the concept and ensure that stakeholders' perspectives are considered. Consequently, each phase of a concept development process might include knowledge gathering and exchange, increasing the level of concretization, i.e., from broad discussion on core concept components to definition of operational products.

Regardless of which approach, "for" or "with practice," there is always a risk that certain parties will take advantage and use such concepts to their benefits (Porter and Davoudi 2012, p. 333). Concerns that fuzzy concepts could 
be (deliberately) misunderstood and misused can thus not be dismissed (Sussams et al. 2015; Nesshöver et al. 2017; Wang and Banzhaf 2018). Participants and especially the steering team of such processes thus need to consider questions of power, institutions, and availability of resources between different actors. In similar future approaches, potential biases could be reduced by involving a facilitator that is specifically trained to ensure a transparent and fair process (Reed 2008, p. 2425).

Regarding transferability of novel concepts, caution is especially warranted when concepts originating in wealthy countries with a high degree of institutionalization and professionalization in planning are transferred to countries with a lack of such structures and financial resources. (Lindley et al. 2018) for sub-Saharan Africa and (Breen et al. 2020) for Latin America refer to (often unintentional) effects of GI planning that fails to correspond with local social, ecological and political complexity, including enhanced environmental injustice and poverty, destruction of traditional indigenous practices or local heritage and spiritual connections, as well as lack of resources and capacities of local stakeholders and institutions. However, novel concepts can spark new, more sustainable planning approaches if they are critically explored and discussed with stakeholders that have a good understanding of social, ecological and political aspects, including the voices of minorities who might be affected by planning consequences (Pauleit et al. 2021).

\subsection{Limitations of the study approach}

Despite the transdisciplinary approach's aim at equal partnerships, power and resources are often unevenly distributed, and questions of justice abound (Gerlak and Zuniga-Teran 2020; Menny et al. 2018). In the studied cases, the researchers were committed to developing concepts in accordance with stakeholder needs and with carefully considered stakeholder input, but it cannot be ruled out that they shaped the outcomes based on their own biases and perspectives. With our study, we hope to at least shed light on the role fuzzy concepts could play in involving stakeholders as partners from an early stage and how their involvement can help to develop results that correspond with practitioner needs.

Due to our focus on influential aspects in different phases of concept development processes and their outcomes, we did not assess the representativeness of the involved stakeholders, the inclusivity of the processes nor if the methods for involvement were perceived as adequate and fair. In future approaches to concept development, attention is thus required on involving a representative spectrum of stakeholder groups and reducing barriers for participation (i.e., Reed 2008). This requires a critical reflection of political agendas and ideologies (i.e., prioritization of social, ecological or economic values at the expense of other values) as well as power relations that explicitly or implicitly influence such discourses (Kotsila et al. 2020; Cousins 2021).

In all cases, stakeholders entered the process of concept development with different perspectives and values. However, in this study, we could not evaluate whether individual stakeholders changed their perspectives towards shared values, or whether the developed concepts provide a frame for different perspectives to co-exist alongside each other. More research is needed on the question of if and how such processes can induce changes of perspective towards a certain level of shared values.

Further inquiry is also needed on whether such discursive processes lead to adoption of the concept by the involved stakeholders in their own work or even by a wider audience (i.e., planners in Germany in Case B) and spur new processes of concept adaptation in the long term. In this context, the role of the policy sector should be investigated further, including if and how the uptake of novel concepts in policies induces significant changes in planning practice (Wright 2011, pp. 1015-1016; Lennon 2014; pp. 16-17).

Overall, it needs to be noted that the three cases were research projects and due to the voluntary participation of stakeholders and the absence of direct consequences on their stakes, there was limited potential for conflict as well as direct impacts on stakeholders. Even in Case C, the developed plan was legally non-binding. Concept development in a planning context with direct impacts on land use practices or stakeholder benefits will often lead to conflicts that need to be negotiated (for example Opdam et al. 2015, p. 68). Our experiences thus cannot fully translate to discourses that have more direct impacts and, for example, require conflict moderation (Reed et al. 2018, p. 13).

\section{Conclusion}

Our research focuses on the evolution of fuzzy concepts in transdisciplinary discourses and how such processes can be steered. For such concepts, there is no clear prerogative of interpretation and therefore they can open a new space for discourse in which changes to current practice through innovative approaches can be discussed. Attempts to hastily overcome uncertainties linked with fuzzy concepts and the exclusion of stakeholder groups from such processes might hamper this transformative potential. A discursive concept 
development process, bringing different arenas together, should thus be initiated early in any new context. Such a transdisciplinary approach should include a critical reflection of the possible understanding(s) against the specific context, an opening discussion about stakeholders' perspectives and priorities, and adaptation of concepts. This might make for a "fuzzy" start, but allows shaping a concept that is useful and acceptable for diverse stakeholders.

With a balance between clear concept framing and flexibility, we argue that such concepts can guide shared understandings about governing nature in urban and peri-urban

regions, while still accounting for complex planning and policy contexts. However, gradual differences such as wording and priorities can be crucial for stakeholders to adopt a novel concept. Researchers working on concepts such as GI, ES, or NBS that aim at real-life impact should invest in transdisciplinary discourses, either in the limited form of consulting experts from policy and planning or through fully co-creative approaches.

\section{Appendix}

Table 3 Comparison of planning principles that have been selected based on literature and refined set after involvement of planning practice perspectives in Case A

Initial set of principles (based on the literature; Davies et al. 2015, pp. 14-15)
Final set of principles (after several rounds of discussions within research consortium, consultation of stakeholders and analysis of planning practice; Hansen et al. 2017a, part B)

\section{Connectivity}

Multifunctionality

Green-grey integration

(Mentioned in the definition as underlying logic)

(Mentioned in the definition as underlying logic)

(Considered as precondition; at least one of both closely links to each principle) Social inclusion 


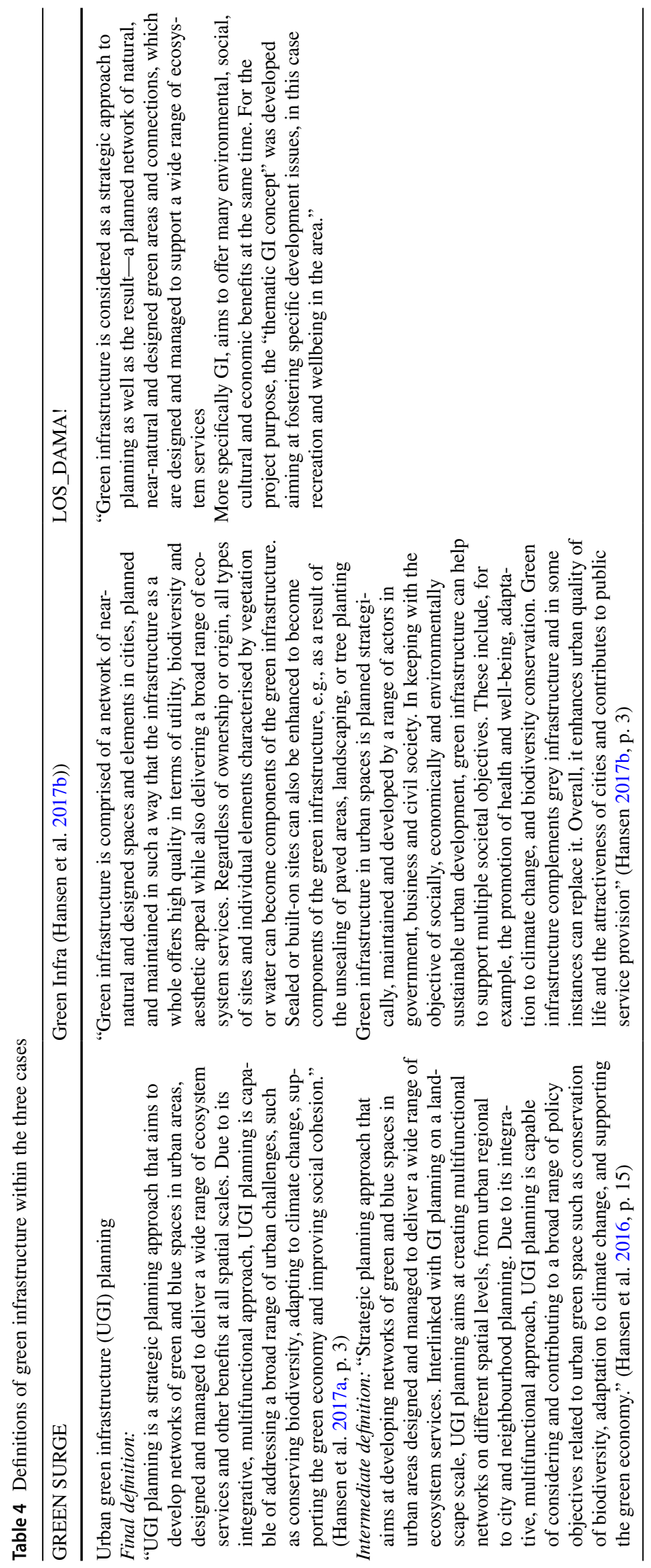


Table 5 Comparison of GI principles that had been defined in the three cases

\begin{tabular}{|c|c|c|}
\hline $\begin{array}{l}\text { GREEN SURGE } \\
\text { (Hansen et al. 2017a, } \\
\text { part B) }\end{array}$ & $\begin{array}{l}\text { GreenInfra (Hansen } \\
\text { et al. 2017b, p. } 3 \text {, } \\
\text { Chap. 2.3) }\end{array}$ & LOS_DAMA! \\
\hline Multifunctionality & $\begin{array}{l}\text { Foster multiple use } \\
\text { and diversity }\end{array}$ & Multifunctionality \\
\hline Connectivity & Create linkages & Connectivity \\
\hline $\begin{array}{l}\text { Green-grey integra- } \\
\text { tion }\end{array}$ & $\begin{array}{l}\text { Green and grey } \\
\text { together }\end{array}$ & $\begin{array}{l}\text { Balance between } \\
\text { development and } \\
\text { conservation }\end{array}$ \\
\hline Social inclusion & $\begin{array}{l}\text { Encourage coop- } \\
\text { erative efforts and } \\
\text { alliances }\end{array}$ & Accessibility \\
\hline- & Improve qualities & Attractiveness \\
\hline
\end{tabular}

Funding Open Access funding enabled and organized by Projekt DEAL. This research has benefited from the authors' participation in the EU Seventh Framework Programme funded GREEN SURGE project (2013-2017; FP7-ENV.2013.6.2-5-603567) and the German project GreenInfra (2016-2017, FKZ 351582 0800) funded by the Federal Agency for Nature Conservation (BfN) and Federal Ministry for the Environment, Nature Conservation and Nuclear Safety (BMU), and in the LOS_DAMA! project (2016-2019) which was co-financed by the European Regional Development Fund (ERDF) within the Interreg Alpine Space Programme of the European Union (ASP 383).

Availability of data and materials This study represents a synthesis of written material created during the analyzed projects, which is mostly online available on the respective project's or contracting organization's websites in grey reports and other publications in English, German or Slovenian, as well as minutes, notes and recollections of the involved researchers. Secondary sources include publicly available information and GIS data. Original case narratives as well as unpublished case material can be made available upon request.

\section{Declaration}

Conflict of interest The authors declare that they have no known financial interests or personal relationships that could have appeared to influence the work reported in the paper. We thank all the other project partners for their efforts in collaboration.

Open Access This article is licensed under a Creative Commons Attribution 4.0 International License, which permits use, sharing, adaptation, distribution and reproduction in any medium or format, as long as you give appropriate credit to the original author(s) and the source, provide a link to the Creative Commons licence, and indicate if changes were made. The images or other third party material in this article are included in the article's Creative Commons licence, unless indicated otherwise in a credit line to the material. If material is not included in the article's Creative Commons licence and your intended use is not permitted by statutory regulation or exceeds the permitted use, you will need to obtain permission directly from the copyright holder. To view a copy of this licence, visit http://creativecommons.org/licenses/by/4.0/.

\section{References}

Abson DJ, von Wehrden H, Baumgärtner S, Fischer J, Hanspach J, Härdtle W et al (2014) Ecosystem services as a boundary object for sustainability. Ecol Econ 103:29-37. https://doi.org/10.1016/j. ecolecon.2014.04.012

Albert C, von Haaren C (2014) Implications of applying the green infrastructure concept in landscape planning for ecosystem services in peri-urban areas: an expert survey and case study. Plan Pract Res 44(5):1-16. https://doi.org/10.1080/02697459.2014. 973683

Benedict MA, McMahon E (2006) Green infrastructure. Linking landscapes and communities. Island Press, Washington, DC

BfN (2017) Federal Green Infrastructure Concept. Edited by German Federal Agency for Nature Conservation (BfN). Available online at https://www.bfn.de/themen/planung/bundeskonzept-grueneinfrastruktur.html

BMUB (2018) White Paper. Green Spaces in the City-For a more liveable future. Edited by Federal Ministry for the Environment, Nature Conservation, Building and Nuclear Safety (BMUB). Berlin

Brand FS, Jax K (2007) Focusing the meaning(s) of resilience: resilience as a descriptive concept and a boundary object. E\&S. https://doi.org/10.5751/ES-02029-120123

Breen A, Giannotti E, Flores Molina M, Vásquez A (2020) From "government to governance"? A systematic literature review of research for urban green infrastructure management in Latin America. Front Sustain Cities. https://doi.org/10.3389/frsc.2020. 572360

Cortekar J, Bender S, Brune M, Groth M (2016) Why climate change adaptation in cities needs customised and flexible climate services. Clim Serv 4:42-51. https://doi.org/10.1016/j.cliser.2016. 11.002

Cousins JJ (2021) Justice in nature-based solutions: research and pathways. Sustain Urban Resilient Future 180:106874. https://doi.org/ 10.1016/j.ecolecon.2020.106874

Davies C, Hansen R, Rall E, Pauleit S, Lafortezza R, DeBellis Y, et al (2015) Green infrastructure planning and implementation. The status of European green space planning and implementation based on an analysis of selected European city-regions. (GREEN SURGE report, Deliverable 5.1). Available online at http://green surge.eu/working-packages/wp5/

Davoudi S (2015) Planning as practice of knowing. Plan Theory 14(3):316-331. https://doi.org/10.1177/1473095215575919

Davoudi S, Shaw K, Haider LJ, Quinlan AE, Peterson GD, Wilkinson $C$ et al (2012) Resilience: a bridging concept or a dead end? "Reframing" resilience: challenges for planning theory and practice interacting traps: resilience assessment of a pasture management system in Northern Afghanistan urban resilience: what does it mean in planning practice? Resilience as a useful concept for climate change adaptation? The politics of resilience for planning: a cautionary note. Plan Theory Pract 13(2):299-333. https://doi. org/10.1080/14649357.2012.677124

Drasdo F, Pintarits S, Tournaire G, Brückler M, Ulrici G, LaRiccia L et al (2019) LOS_DAMA! Compendium. Green infrastructure for better living. Edited by City of Munich/Piedmont Region/European Regional Development Fund. Munich. Available online at https://www.alpine-space.eu/projects/los_dama/en/this-is-howwe-do-it/outputs-and-results/landscape-approaches

EEA (2011) Green infrastructure and territorial cohesion. The concept of green infrastructure and its integration into policies using monitoring systems. EEA Technical report No 18/2011, updated on 12/14/2011, checked on 5/24/2012

Eggermont H, Balian E, Azevedo JMN, Beumer V, Brodin T, Claudet $\mathbf{J}$ et al (2015) Nature-based solutions: new influence for 
environmental management and research in Europe. GAIA Ecol. Perspect. Sci. Soc. 24(4):243-248. https://doi.org/10.14512/gaia. 24.4.9

European Commission (2013) Communication from the Commission to the European Parliament, the council, the European Economic and Social Committee and the Committee of the Regions. Green Infrastructure (GI) - Enhancing Europe's Natural Capital. COM (2013) 249 final.

European Commission (2011) Communication from the Commission to the European Parliament, the Council, the Economic and Social Committee and the Committee of the Regions. Our life Insurance, Our Natural Capital: An EU Biodiversity Strategy to 2020. COM (2011) 244 final. Brussels.

Fletcher TD, Shuster W, Hunt WF, Ashley R, Butler D, Arthur S et al (2015) SUDS, LID, BMPs, WSUD and more-the evolution and application of terminology surrounding urban drainage. Urban Water J 12(7):525-542. https://doi.org/10.1080/1573062X.2014. 916314

Frantzeskaki N (2019) Seven lessons for planning nature-based solutions in cities. Environ Sci Policy 93:101-111. https://doi.org/10. 1016/j.envsci.2018.12.033

Garmendia E, Apostolopoulou E, Adams WM, Bormpoudakis D (2016) Biodiversity and Green Infrastructure in Europe: boundary object or ecological trap? Land Use Policy 56:315-319. https:// doi.org/10.1016/j.landusepol.2016.04.003

Gavrilidis A-A, Popa A-M, Nita M-R, Onose D-A, Badiu D-L (2020) Planning the "unknown": perception of urban green infrastructure concept in Romania. Urban Urban Greece 51:126649. https://doi. org/10.1016/j.ufug.2020.126649

Gerlak AK, Zuniga-Teran A (2020) Addressing injustice in green infrastructure through socio-ecological practice: What is the role of university-community partnerships? Socio Ecol Pract Res 2(2):149-159. https://doi.org/10.1007/s42532-020-00052-5

Grădinaru SR, Hersperger AM (2018) Green infrastructure in strategic spatial plans: evidence from European urban regions. Urban For Urban Green. https://doi.org/10.1016/j.ufug.2018.04.018

Hansen R, Pauleit S (2014) From multifunctionality to multiple ecosystem services? A conceptual framework for multifunctionality in green infrastructure planning for urban areas. Ambio 43(4):516-529. https://doi.org/10.1007/s13280-014-0510-2

Hansen R, Rolf W, Santos A, Luz AC Száraz L, Tosics I, et al (2016) Advanced urban green infrastructure planning and implementation. Innovative approaches and strategies from European cities (GREEN SURGE report, Deliverable 5.2.). Available online at http://greensurge.eu/working-packages/wp5/

Hansen R, Born D, Lindschulte K, Rolf W, Bartz R, Schröder A, et al (2018) Grüne Infrastruktur im urbanen Raum: Grundlagen, Planung und Umsetzung in der integrierten Stadtentwicklung. Abschlussbericht zum F+E-Vorhaben „Grüne Infrastruktur im urbanen Raum: Grundlagen, Planung und Umsetzung in der integrierten Stadtentwicklung“. Bonn-Bad Godesberg: BfN (BfNSkripten, 503). Available online at https://doi.org/10.19217/skr50 3

Hansen R, Rolf W, Pauleit S, Born D, Bartz R, Kowarik I, et al (2017b) Urban green infrastructure. A foundation of attractive and sustainable cities. Pointers for municipal practice

Hansen R, Pauleit S, Rolf W, van Lierop M (2019) Grüne Infrastruktur als innovativer Planungsansatz für nachhaltige und inklusive Stadtentwicklung. Nachrichten der ARL 3:11-15

Hansen R, Rall E, Chapman E, Rolf W, Pauleit S (eds) (2017a) Urban green infrastructure planning. A guide for practitioners. (GREEN SURGE report, Deliverable 5.3.). Available online at http://green surge.eu/working-packages/wp5/

Horwood K (2011) Green infrastructure: reconciling urban green space and regional economic development: lessons learnt from experience in England's north-west region. Local Environ 16(10):963-975. https://doi.org/10.1080/13549839.2011.607157

Innes JE, Booher DE (1999) Consensus building and complex adaptive systems. J Am Plann Assoc 65(4):412-423. https://doi.org/ $10.1080 / 01944369908976071$

Jacobs M (2011) Sustainable development as a contested Concept. In: Dobson A (ed) Fairness and futurity. Essays on environmental sustainability and social justice. [Nachdr.]. Oxford University Press, Oxford, pp 21-45

Kahl M, Gehrcke-Schleithoff M (2016) Diskussion um das Weißbuch Stadtgrün. Bundesregierung definiert die eigene Strategie zur urbanen grünen Infrastruktur. Naturschutz und Landschaftsplanung (6), pp 200-202. Available online at https://www.nul-online. de/artikel.dll/NuL06-16-Inhalt-200-204-1_NTA3Mzg4Nw.PDF? $\mathrm{UID}=1 \mathrm{~A} 0 \mathrm{C} 41 \mathrm{~A} 283 \mathrm{E} 614 \mathrm{ADCF} 591 \mathrm{FC} 7 \mathrm{~B} 811797 \mathrm{ACD} 766 \mathrm{EC} 1$ 33902B, checked on $7 / 8 / 2020$

Kambites C, Owen S (2006) Renewed prospects for green infrastructure planning in the UK. Plan Pract Res 21(4):483-496. https:// doi.org/10.1080/02697450601173413

Kotsila P, Anguelovski I, Baró F, Langemeyer J, Sekulova F, Connolly JJT (2020) Nature-based solutions as discursive tools and contested practices in urban nature's neoliberalisation processes. Environ Plan Nat Space 16(2):251484862090143. https://doi.org/ $10.1177 / 2514848620901437$

Lennon M (2014) Green infrastructure and planning policy: a critical assessment. Local Environ. https://doi.org/10.1080/13549 839.2014.880411

Liao K-H (2019) The socio-ecological practice of building bluegreen infrastructure in high-density cities: what does the ABC Waters Program in Singapore tell us? Socio Ecol Pract Res 1(1):67-81. https://doi.org/10.1007/s42532-019-00009-3

Lindley S, Pauleit S, Yeshitela K, Cilliers S, Shackleton C (2018) Rethinking urban green infrastructure and ecosystem services from the perspective of sub-Saharan African cities. Landsc Urban Plan 180:328-338. https://doi.org/10.1016/j.landurbplan. 2018.08.016

Luederitz C, Brink E, Gralla F, Hermelingmeier V, Meyer M, Niven L et al (2015) A review of urban ecosystem services: six key challenges for future research. Ecosyst Serv 14:98-112. https:// doi.org/10.1016/j.ecoser.2015.05.001

Markusen A (1999) Fuzzy concepts, scanty evidence, policy distance: the case for rigour and policy relevance in critical regional studies. Reg Stud 33(9):869-884. https://doi.org/10. 1080/00343409950075506

Meerow S (2020) The politics of multifunctional green infrastructure planning in New York City. Cities 100:102621. https://doi.org/ 10.1016/j.cities.2020.102621

Mell IC (2009) Can green infrastructure promote urban sustainability? Proc ICE Eng Sustain 162(1):23-34. https://doi.org/10. 1680/ensu.2009.162.1.23

Mell I, Allin S, Reimer M, Wilker J (2017) Strategic green infrastructure planning in Germany and the UK: a transnational evaluation of the evolution of urban greening policy and practice. Int Plan Stud 22(4):333-349. https://doi.org/10.1080/13563475. 2017.1291334

Menny M, Palgan YV, McCormick K (2018) Urban living labs and the role of users in co-creation. GAIA Ecol Perspect Sci Soc 27(1):68-77. https://doi.org/10.14512/gaia.27.S1.14

Monteiro R, Ferreira JC, Antunes P (2020) Green infrastructure planning principles: an integrated literature review. Land 9(12):525. https://doi.org/10.3390/land9120525

Nesshöver C, Assmuth T, Irvine KN, Rusch GM, Waylen KA, Delbaere B et al (2017) The science, policy and practice of naturebased solutions: an interdisciplinary perspective. Sci Total 
Environ 579:1215-1227. https://doi.org/10.1016/j.scitotenv. 2016.11.106

Nordh H, Olafsson AS (2020) Plans for urban green infrastructure in Scandinavia. J Environ Plan Manag. https://doi.org/10.1080/ 09640568.2020.1787960

Opdam P, Nassauer JI, Wang Z, Albert C, Bentrup G, Castella J-C et al (2013) Science for action at the local landscape scale. Landsc Ecol 28(8):1439-1445. https://doi.org/10.1007/s10980-013-9925-6

Opdam P, Westerink J, Vos C, de Vries B (2015) The role and evolution of boundary concepts in transdisciplinary landscape planning. Plan Theory Pract 16(1):63-78. https://doi.org/10.1080/14649 357.2014.997786

Pauleit S, Zölch T, Hansen R, Randrup TB, van den Konijnendijk Bosch C (2017) Nature-based solutions and climate changefour shades of green. In: Kabisch N, Korn H, Stadler J, Bonn A (eds) Nature-based solutions to climate change adaptation in urban areas. Linkages between science, policy and practice, vol 29. Springer; Springer Open (Theory and Practice of Urban Sustainability Transitions), Cham, pp 29-49

Pauleit S, Vásquez A, Maruthaveeran S, Liu L, Cilliers S (2021) Urban green infrastructure in the Global South. In: Shackelton C, Cilliers SS, Davoren E, Du Toit MJ (eds) Urban ecology in the global South. SpringerNature, Cham, Switzerland

Pauleit S, Liu L, Ahern J, Kazmierczak A (2011) Multifunctional green infrastructure planning to promote ecological services in the city. In: Niemelä J (ed) Urban ecology. Patterns, processes, and applications. Oxford University Press, Oxford (Oxford biology), pp 272-285

Porter L, Davoudi S (2012) The politics of resilience for planning. A cautionary note. Plann Theory Pract 13(2):329-333

Rall EL, Kabisch N, Hansen R (2015) A comparative exploration of uptake and potential application of ecosystem services in urban planning. Ecosyst Serv 16:230-242. https://doi.org/10.1016/j. ecoser.2015.10.005

Reed MS (2008) Stakeholder participation for environmental management: a literature review. Biol Cons 141(10):2417-2431. https:// doi.org/10.1016/j.biocon.2008.07.014

Reed MS, Vella S, Challies E, de Vente J, Frewer L, Hohenwallner-Ries $\mathrm{D}$ et al (2018) A theory of participation: what makes stakeholder and public engagement in environmental management work? Restor Ecol 26:S7-S17. https://doi.org/10.1111/rec.12541

Robinson DA, Hockley N, Cooper DM, Emmett BA, Keith AM, Lebron I et al (2013) Natural capital and ecosystem services, developing an appropriate soils framework as a basis for valuation. Soil Biol Biochem 57:1023-1033. https://doi.org/10.1016/j.soilbio.2012. 09.008

Roe M, Mell I (2013) Negotiating value and priorities: evaluating the demands of green infrastructure development. J Environ Plan Manag 56(5):650-673. https://doi.org/10.1080/09640568.2012. 693454

Schröter M, van der Zanden EH, van Oudenhoven APE, Remme RP, Serna-Chavez HM, de Groot RS, Opdam P (2014) Ecosystem services as a contested concept: a synthesis of critique and counter-arguments. Conserv Lett. https://doi.org/10.1111/conl.12091

Seiwert A, Rößler S (2020) Understanding the term green infrastructure: origins, rationales, semantic content and purposes as well as its relevance for application in spatial planning. Land Use Policy 97:104785. https://doi.org/10.1016/j.landusepol.2020.104785
Shi L (2020) Beyond flood risk reduction: how can green infrastructure advance both social justice and regional impact? Socio Ecol Pract Res. https://doi.org/10.1007/s42532-020-00065-0

Singh H, Gupta MM, Meitzler T, Hou Z-G, Garg KK, Solo AMG, Zadeh LA (2013) Real-life applications of fuzzy logic. Adv Fuzzy Syst. https://doi.org/10.1155/2013/581879

Star SL (2010) This is not a boundary object: reflections on the origin of a concept. Sci Technol Human Values 35(5):601-617. https:// doi.org/10.1177/0162243910377624

Star SL, Griesemer JR (1989) Institutional ecology, 'translations' and boundary objects: amateurs and professionals in Berkeley's museum of vertebrate zoology, 1907-39. Soc Stud Sci 19(3):387420. https://doi.org/10.1177/030631289019003001

Star SL, Ruhleder K (1996) Steps toward an ecology of infrastructure: design and access for large information spaces. Inform Syst Res 7(1):111-134. https://doi.org/10.1287/isre.7.1.111

Steger C, Hirsch S, Evers C, Branoff B, Petrova M, Nielsen-Pincus M et al (2018) Ecosystem services as boundary objects for transdisciplinary collaboration. Ecol Econ 143:153-160. https://doi.org/ 10.1016/j.ecolecon.2017.07.016

Sundseth K, Sylwester A (2009) Towards green infrastructure for Europe. In: Proceedings of the European Commission workshop, Brussels

Sussams LW, Sheate WR, Eales RP (2015) Green infrastructure as a climate change adaptation policy intervention: muddying the waters or clearing a path to a more secure future? J Environ Manag 147:184-193. https://doi.org/10.1016/j.jenvman.2014. 09.003

Tress G, Tress B, Fry G (2005) Clarifying integrative research concepts in landscape ecology. Landsc Ecol 20(4):479-493. https://doi.org/ 10.1007/s10980-004-3290-4

Turnhout E (2009) The effectiveness of boundary objects: the case of ecological indicators. Sci Pub Pol 36(5):403-412. https://doi.org/ 10.3152/030234209X442007

UIRS (2019) Recreational GI plan for Ljubljana Marsh Nature Park. UIRS/LOS_DAMA! Green infrastructure for better living in Ljubljana Marsh Nature Park [Poster]. Munich. Available online at https://www.alpine-space.eu/projects/los_dama-/results/flyer_ poster/final-poster/ld_poster_uirs.pdf

van der Jagt APN, Raven R, Dorst H, Runhaar H (2019) Nature-based innovation systems. Environ Innov Soc Trans. https://doi.org/10. 1016/j.eist.2019.09.005

van Assche K, Beunen R, Verweij S (2020) Learning from other places and their plans: comparative learning in and for planning systems. UP 5(1): 1. https://doi.org/10.17645/up.v5i1.2938 .

van Lierop M, Stockinger C, Drasdo F, Mertelmeyer L, Lampert M, Tournaire G et al (2019) LOS_DAMA! Toolbox. Edited by City of Munich, Department of Urban Planning and European Regional Development Fund. Munich. Available online at https://www. alpine-space.eu/projects/los_dama/en/this-is-how-we-do-it/outpu ts-and-results/toolbox

Walmsley A (2006) Greenways: multiplying and diversifying in the 21st century. Landsc Urban Plan 76(1-4):252-290. https://doi. org/10.1016/j.landurbplan.2004.09.036 
Wang J, Banzhaf E (2018) Towards a better understanding of Green Infrastructure: a critical review. Ecol Ind 85:758-772. https://doi. org/10.1016/j.ecolind.2017.09.018

Westerink J, Lagendijk A, Dühr S, van der Jagt P, Kempenaar A (2013) Contested spaces? The use of place concepts to communicate visions for peri-urban areas. Eur Plan Stud 21(6):780-800. https:// doi.org/10.1080/09654313.2012.665042

Wright H (2011) Understanding green infrastructure: the development of a contested concept in England. Local Environ 16(10):10031019. https://doi.org/10.1080/13549839.2011.631993

Yin RK (2010) Case study research. Design and methods, 4th ed. Thousand Oaks, Calif: Sage (Applied social research methods series, 5)

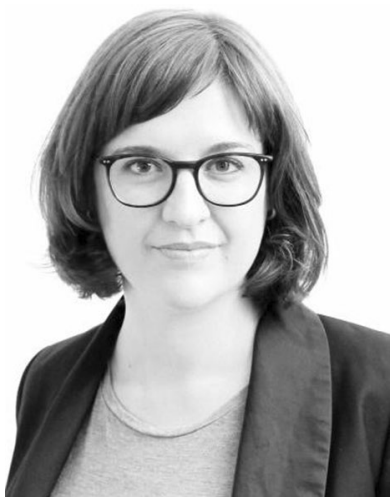

Dr. Rieke Hansen is the Professor for Open Space and Ecological Urban Design at Hochschule Geisenheim University, Germany. Her research focuses on the innovative potential of concepts such as green infrastructure, ecosystem services and nature-based solutions for sustainable urban development. In this context, she has studied landscape and open space planning city regions in Germany, Europe, and the USA.

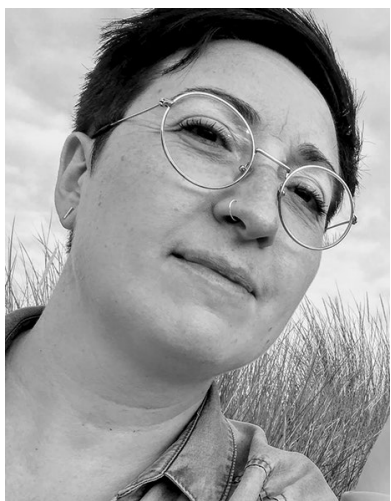

Martina van Lierop is a research associate at the Chair of Strategic Landscape Planning and Management at the Technical University of Munich. She is a landscape architect and landscape planner with experience in diverse interdisciplinary and participatory projects in research and practice in the Netherlands, Germany as well as Russia, China and Palestine. She studies approaches, strategies and methods for the governance and implementation of green infrastructure and related concepts such as nature-based solutions in collaborative and participatory processes.

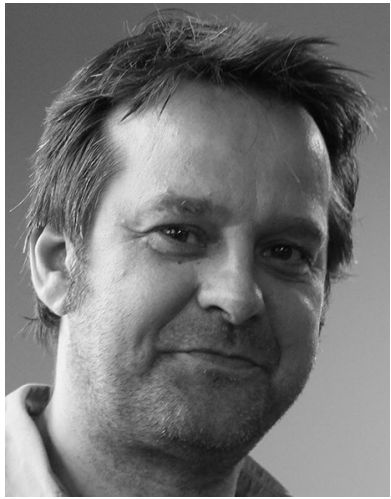

Dr. Werner Rolf is a research and teaching associate for strategic landscape planning and management at the Technical University of Munich, Germany. His research focuses on integrative landscape approaches, land-use modeling, scenario development, collaborative and participatory spatial planning. He has international experience on applied research in rural and urban landscapes at different scales across Europe.

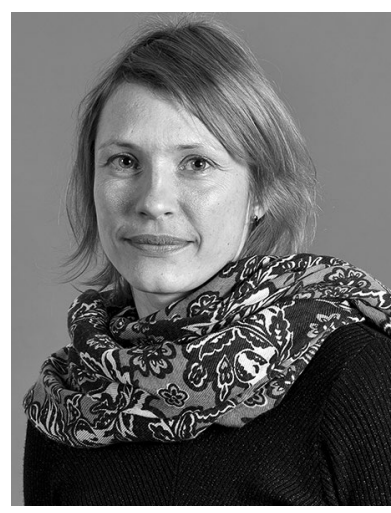

Dr. Damjana Gantar works at the Urban Planning Institute of the Republic of Slovenia (UIRS) as senior researcher and project leader of multidisciplinary transnational and national projects. Main research interests are landscape changes and scenarios, preservation of quality and cultural heritage in the countryside in correlation to various drivers such as policies or demographic changes. She is editor-in-chief of the scientific journal Urbani izziv.

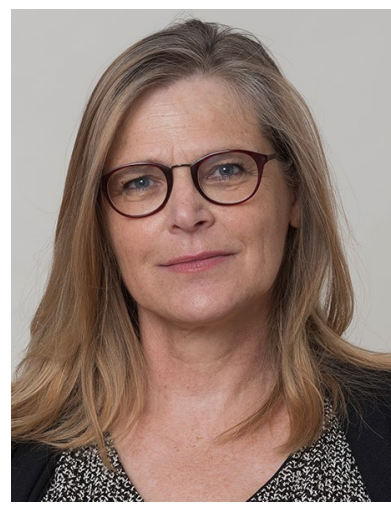

Ina Šuklje Erjavec (B.Sc. and M.Sc. in Landscape Architecture) works at the Urban Planning Institute of the Republic of Slovenia (UIRS) as a senior researcher and a project leader at the local, national, and international level, preparing methodologies and guidelines for green space strategies, urban landscape typologies, models for spatial quality evaluation and similar.

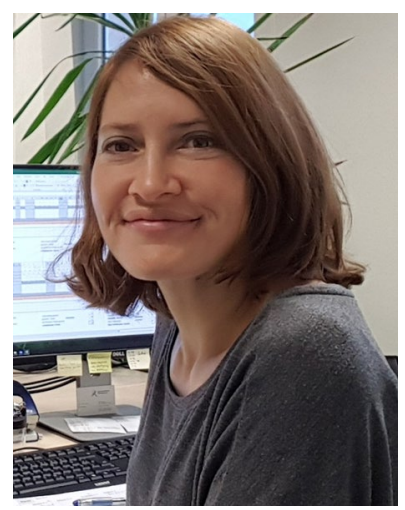

Dr. Emily Lorance Rall is an open space planner for the Regional Planning Authority of Ostwürttemberg. Before that she was as a research scientist at the Technical University of Munich, where she completed her dissertation in 2018 with a focus on integrating cultural ecosystem services mapping into urban green infrastructure planning.

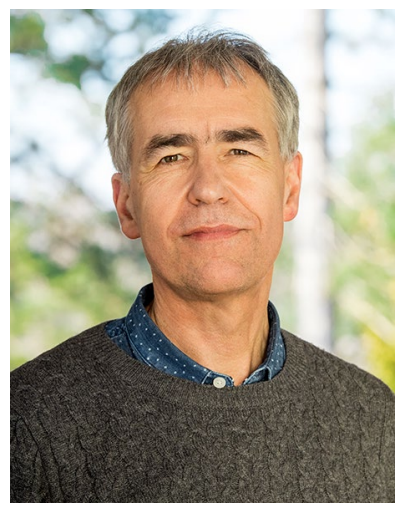

Professor Stephan Pauleit leads the Chair for Strategic Landscape Planning and Management at Munich Technical University. $\mathrm{He}$ is an expert in landscape planning and urban ecology and has developed a special interest in green infrastructure planning, nature-based solutions, adaptation strategies to climate change in the urban environment, and urban forestry. He directs the "Centre for Urban Ecology and Climate Change Adaptation" at the Technical University of Munich. 